This PDF is a selection from a published volume from the National Bureau of Economic Research

Volume Title: Commodity Prices and Markets, East Asia Seminar on Economics, Volume 20

Volume Author/Editor: Takatoshi Ito and Andrew K. Rose, editors

Volume Publisher: University of Chicago Press

Volume ISBN: 0-226-38689-9

ISBN13: 978-0-226-38689-8

Volume URL: http://www.nber.org/books/ito_09-1

Conference Date: June 26-27, 2009

Publication Date: February 2011

Chapter Title: Pass-Through of Oil Prices to Japanese Domestic Prices

Chapter Authors: Etsuro Shioji, Taisuke Uchino

Chapter URL: http://www.nber.org/chapters/c11880

Chapter pages in book: (155 - 189) 


\title{
Pass-Through of Oil Prices to Japanese Domestic Prices
}

\author{
Etsuro Shioji and Taisuke Uchino
}

\subsection{Introduction}

This chapter studies the effects of oil prices on domestic prices using the Japanese data. Recent dramatic surge and fall of crude oil prices have renewed interest in their effects on domestic economies. In the literature, many authors have documented (in many cases using the U.S. data) weakening impacts of oil prices on the domestic economy. For example, Hooker (1996) finds that impacts of oil prices on U.S. gross domestic product (GDR) and U.S. unemployment have diminished since the mid-1970s. Hooker (2002), which is more relevant for the current analysis, finds that the impact of oil prices on U.S. domestic inflation has been weakened significantly since around 1980. De Gregorio, Landerretche, and Neilson (2007) apply a Hooker-type approach to a number of industrialized as well as

Etsuro Shioji is a professor in the Graduate School of Economics at Hitotsubashi University. Taisuke Uchino is a researcher in the Global Centers of Excellence (COE) program, and the Research Unit for Statistical and Empirical Analysis in Social Sciences, Hitotsubashi University.

A part of this chapter is based on research we have conducted at the Research and Statistics Department of the Bank of Japan. We would like to thank members of the Department, especially Kazuo Monma, Munehisa Kasuya, and Masahiro Higo for helpful comments and discussions on our research. We also thank Takatoshi Ito for insightful suggestions at an early stage of this research. We are grateful to participants of the 20th East Asian Economic Seminar (Hong Kong, June 26-27, 2009), especially the discussants Donghyun Park and Yuko Hashimoto, as well as the organizers (Andrew Rose and Takatoshi Ito) for many invaluable comments that have led to substantial improvement of the chapter. We also would like to thank two anonymous referees for their insightful comments. Shioji thanks the "Understanding Inflation Dynamics of the Japanese Economy" project of Hitotsubashi University for financial assistance, and Uchino thanks the Hitotsubashi University Global COE Grant "Research unit for statistical and empirical analysis in social sciences." 
developing countries and confirm his findings. They also estimate rolling vector autoregression (VARs) for those countries and again confirm declines in oil price pass-through. Blanchard and Gali (2007) also estimate rolling VARs for the United States. They also estimate regular VARs for the United States and other industrialized countries, splitting the sample at 1984. They arrive at similar conclusions as the previous authors. ${ }^{1}$ Causes behind these changes have also attracted attention of macroeconomists. As Blinder and Rudd (2009) summarize succinctly, three possible candidates have been widely considered. First is increased credibility of monetary policy. Second is greater wage flexibility. Third is changing industrial structure after the two oil crises; that is, the substitution effects: firms have shifted away from energy-using technology to energy-saving technology. ${ }^{2}$

In this chapter, we study the Japanese data using time series analysis technique and confirm the tendency of declining pass-through of oil prices to domestic prices, for the period 1980 to 2000 . We find that the main driving force behind this was different from any of the previous three. Investigation of the Japanese input-output (I-O) tables reveals that changes in the cost structure alone go a long way toward explaining the declining pass-through. In that sense, at a first glance, our results might seem consistent with the third hypothesis mentioned before. But a further analysis indicates that the main reason behind the changing cost structure was not the substitution effects or changes in relative quantities: it was rather changes in the relative prices that played a more important role. Put simply, as oil became cheaper, it became less and less important in the overall cost structure (due partially to a relatively low degree of substitution between oil and nonoil inputs), and thus the pricing behaviors of the firms became less responsive to its prices. The real factor or the substitution effect did play some role, mainly in the short

1. However, they find inexplicable impulse response results for Japan.

2. Blanchard and Gali (2007) construct a New Keynesian dynamic stochastic general equilibrium (DSGE) model that incorporates all three elements. Their simulations show that all three have contributed to declining pass-through of oil prices. Kilian (2008) mentions two other candidates: one is a U.S.-specific reason (structure of the automobile industry), which is less relevant here. The other is a difference in the fundamental causes behind different episodes of oil price surges: it is hypothesized that the oil price increase in the 2000s was a consequence of a worldwide demand increase rather than a supply shock. For inflation, however, it is not clear if demand-driven oil price increase should have either stronger or weaker effects on domestic prices. De Gregorio, Landerretche, and Neilson (2007) argue that a positive demand shock would tend to appreciate currencies of commodity importing countries, thus mitigating the effects of higher oil prices. De Gregorio, Landerretche, and Neilson (2007) also offer an additional candidate for the cause of the pass-through decline: under a low inflation environment, firms change prices less frequently, and, as a consequence, oil price increases are not easily passed through to domestic prices. Another important hypothesis is that oil prices were not so influential to begin with: it was another shock that occurred around the same time period that had much impact on the economy (the most notable candidate is an excessively tight monetary policy). Refer to, for example, Bernanke, Gertler, and Watson (1997). Blinder and Rudd (2008), on the other hand, support the supply-shock view of the "Great Inflation" of the 1970s and the 1980s. 
run, but its role in the long-term decline in the pass-through rate was relatively minor (with some exceptions, such as the electricity sector). ${ }^{3}$ We also document the importance of taking into account features of the Japanese oil-related taxation system.

This chapter is a sequel to Shioji and Uchino (2009). In that paper, we estimate a series of VARs with oil prices, the exchange rate, and various indicators of domestic prices, splitting the entire sample period into two subperiods: the first is the period February 1976 to December 1989, and the second is from January 1990 to January 2009. It is reported that, as a general tendency, pass-through of both oil prices and the exchange rate tend to decline between the two periods. Then, those results are compared to the results of our study on the Japanese input-output table, though we use only information from the I-O tables only for the years 1980, 1985, 1990, 1995, and 2000 in that paper.

This chapter extends the previous analysis in three important respects. First, the VAR analysis in the previous paper does not reveal how the passthrough rate evolved over time. Note that, if changes in the cost structure were the main reason behind its decline, we might expect it to happen gradually over time, rather than experiencing a onetime structural break. To pursue this issue further, in this chapter we estimate time-varying parameter (or TVP-) VARs (refer to, for example, Kim and Nelson [1999]). It is expected that this approach will help detect timing of structural changes, and thus give us more hint on the causes behind the decline in the pass-through rate. Like in Shioji and Uchino (2009), we compare the time series estimation results with predictions from the input-output table analysis, to see how much of the observed changes in the pass-through rate can be explained by cost structure related reasons. The second feature of this chapter is that we conduct a detailed analysis of the Japanese input output table for the 2000s (years 2000 to 2010). Particularly, we pay a close attention to the mid- to late 2000s; that is, the period of a dramatic rise and a fall of oil prices.

The rest of the chapter is organized as follows. In section 5.2, we revisit evidence from the simple VARs with split samples, for the sake of comparison with our TVP-VAR results. Section 5.3 presents the results based on the TVP-VARs, and in section 5.4, we compare them with the results of the input-output table results for the period 1980 to 2000. In section 5.5, we turn our attention to the recent periods of volatile oil price movements. Section 5.6 concludes.

3. Among previous studies, Blanchard and Gali (2007) estimate oil shares in both consumption and production, based on the shares of oil and related products in overall nominal value added of the U.S. economy. They compute these shares separately for 1973 and 1997, and use them for their simulations. In that sense, they do not distinguish between relative quantities changes and relative price changes. 


\subsection{Evidence from Regular VARs}

Japan imports over 99 percent of crude oil it uses from abroad, and is thus considered to be vulnerable to its price changes. Figure 5.1 plots three variables. First is the World Crude Oil Price Index ("OIL" for short). This variable is defined in U.S. dollars. We use the International Financial Statistics' (IFS's) "World Petroleum: Average Crude Price" monthly averages, all the way up to October 2008. As we could not obtain this data for the period November 2008 through May 2009, we supplement this with the data on North Sea Brent Spot, which are also monthly averages. Second is the Import Price Index for Crude Oil ("IPI" for short). This variable is denominated in the Japanese yen. It is taken from the Bank of Japan (BOJ)'s Price Indexes Quarterly. Third is Japan's Corporate Goods Price Index (overall average, "CGPI" for short), which corresponds to the wholesale price index in many other countries. The data source is the same as IPI. The figure spans the entire sample period of our analysis, namely from January 1975 to May 2009. The variables are normalized so that their values in January 1990 are all equal to 100. In figure 5.1, note that, despite the surge in the U.S. dollar price of crude oil (namely OIL) in the second half of the 2000s, its yen price (namely IPI) does not surpass its peak in the 1980s until late 2007. This is because the dollar-yen exchange rate changed in favor of the yen between those two periods.

It is often stated that the pass-through rate of oil prices to the domestic

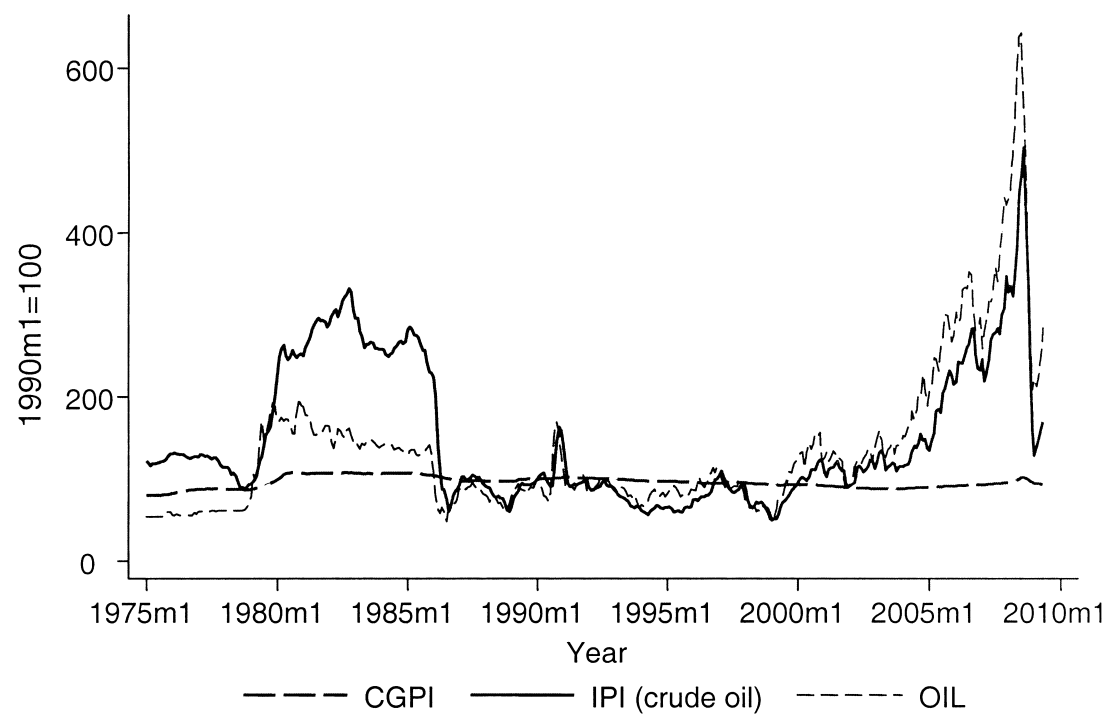

Fig. 5.1 Evolution of OIL, IPI, and CGPI, January $1990=100$

Source: Bank of Japan and International Financial Statistics (IFS). 
prices in Japan has declined in recent years. To see if this claim is verified, we estimate VARs with OIL, IPI, and Japanese domestic prices. In Shioji and Uchino (2009), we estimate VARs with multiple indices of domestic prices: some prices that represent the "upstream" of the production process, such as CGPI, as well as "downstream" prices such as CPI. This approach is in line with Ito and Sato (2008), who study exchange rate pass-through in Asian economies using VARs with multistage domestic prices. Here, instead, we estimate a series of three variables VARs, which includes just one index of domestic prices at a time. The reason is that, when estimating time varying parameter VARs (which will be introduced later), we found that we quickly run out of computer memory if we include four variables or more, with twelve lags. This choice also precludes inclusion of other potential determinants of domestic prices but, as we show in an appendix that is available upon request, our VAR results are robust to inclusion of one more variable, such as industrial production, the exchange rate, and the interest rate.

All the data is monthly. The first sample period is from February 1976 to December 1989 (often referred to as the "first half"), and the second sample period is from January 1990 to May 2009 (often referred to as the "second half"). ${ }^{4}$ Throughout this chapter (including the TVP-VAR part), the lag length is set to equal twelve. We take natural logarithms of all the variables and take their first differences. Reported impulse responses are all cumulative responses (that is, they are the responses of the log level of each variable) to one standard deviation shocks. The impulse response calculations are based on Cholesky decomposition, with OIL treated as the "most" predetermined, and IPI as the second. Although the exchange rate does not appear explicitly (unlike in Shioji and Uchino [2009]), it is implicitly included in our estimation. Note that OIL is in U.S. dollars while IPI is in the Japanese yen. Hence, the difference between the two reflects the dollar-yen exchange rate fluctuations, among other things. An advantage of this approach is that it allows us to control for other factors that influence the difference between OIL and IPI, such as changes in transportation costs and margins charged by shipping firms. To save space, we report only cases that correspond to an OIL shock, and show its own responses (i.e., responses of OIL to OIL) and responses of IPI and domestic price indices. Figure 5.2 reports the case in which the domestic price index is CGPI total. In all the panels reported in this section, the left-hand side figure is for the first half, and the right-hand side is the second half. Also, the dashed lines represent the 95 percentile bands. Panel (A) corresponds to the response of OIL to an OIL shock. Panel (B) is the response of IPI to OIL, and (C) is the response of CGPI to OIL. Note that the scales in Panels (B) and (C) are set in the same way as in (A) for

4. Our choices regarding the beginning of the first half and the last month of the second half are dictated by the data availability (at the time we started this research). The choice of where to break the sample is somewhat arbitrary, except that it roughly corresponds to the beginning of Japan's so-called "lost decade." 
(A) Response of OIL to OIL

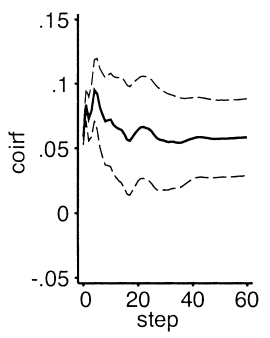

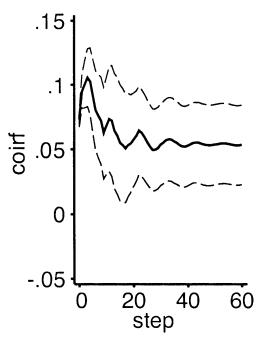

(C) Response of CGPI to OIL
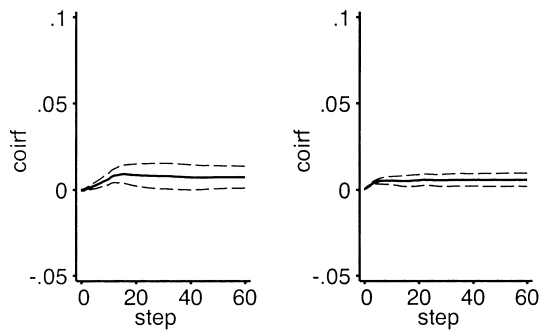

(B) Response of IPI to OIL
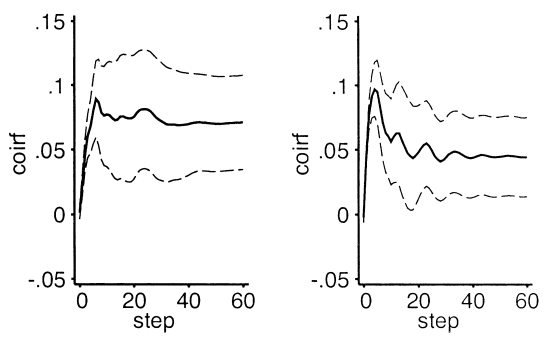

(D) Same as (C), magnified
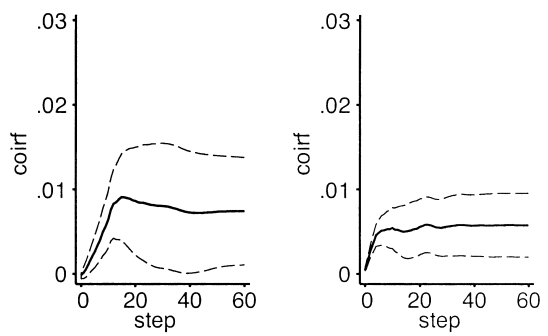

Fig. 5.2 Regular VAR with CGPI, first half (February 1976-December 1989, left) and second half (January 1990-May 2009, right)

the sake of comparison. But this makes the graphs in (C) too small. For that reason, in Panel (D), we present the same graph as in (C) but with a different scale. Note, first, that the sizes of the responses of OIL to an "own shock" are not that different between the first half and the second half (Panel (A)). This means that we can study changes in the magnitudes of pass-through primarily by looking at the responses of domestic prices. ${ }^{5}$ Panel (B) shows that, within six months to one year, changes in the worldwide oil prices are passed onto import prices to Japan, almost fully. Panel (C) shows that the response of CGPI to OIL was small compared with its own response, even during the first half, and that it declined further in the second half (which is more evident in the magnified graphs in (D)).

One of the possible shortcomings of using the overall CGPI is that it is constructed as the weighted average of prices of goods sold at various stages of production. This means that the same oil can be counted many times: as a raw material, as a part of an intermediate input (such as naphtha, ethylene,

5. To illustrate this point, consider the following counterfactual example: suppose that the responses of CGPI to OIL are of about the same size between the two periods, but the response of OIL to itself in the second half is twice as large as that in the first half. In such a case, it is reasonable to conclude that the pass-through rate of OIL to CGPI was halved in the second half. This example suggests importance of looking at the sizes of "own responses" in drawing economic conclusions. 
(A) Response of CGPI-M to OIL

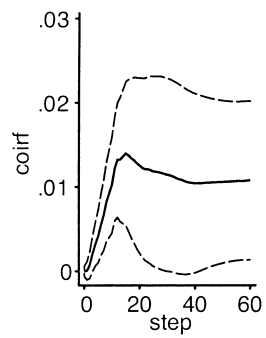

(B) Response of CGPI-C(M) to OIL
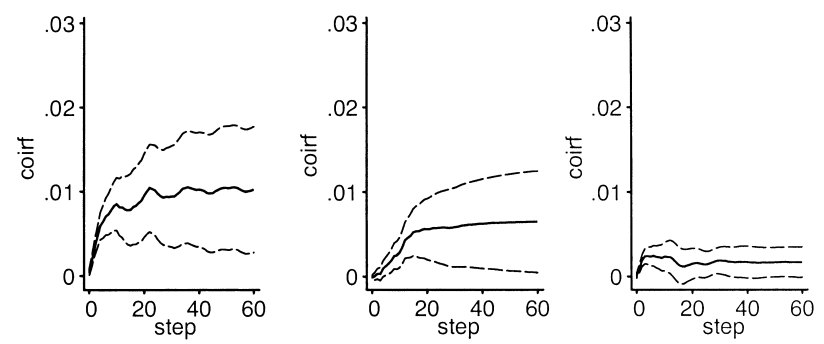

(C) Response of CGPI-K to OIL
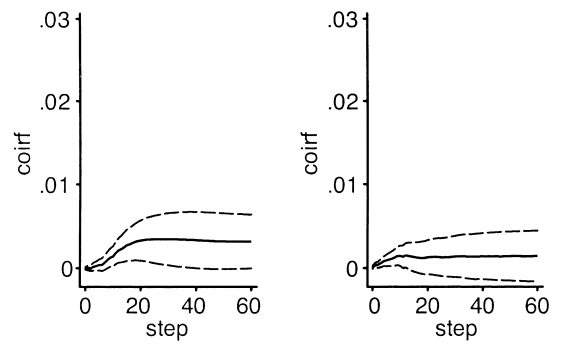

(D) Response of CPI-G(M) to OIL
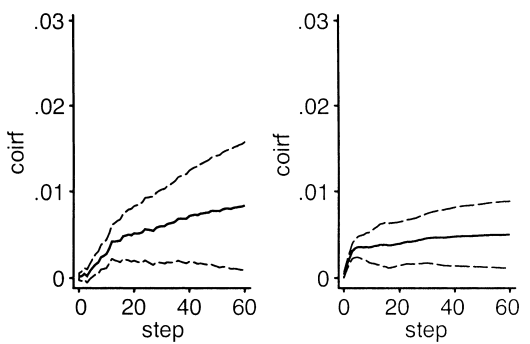

Fig. 5.3 Regular VAR with alternative prices, first half (February 1976-December 1989, left) and second half (January 1990-May 2009, right)

and polyethylene), and as a part of a final product (such as plastic hoses). To minimize this problem, we redo the analysis utilizing the information on CGPI "by stage of demand and use" published by the Bank of Japan. That is, overall CGPI is decomposed into the intermediate goods part and the final goods part. In panel (A) of figure 5.3, we use the average CGPI for intermediate products (domestically produced) only, which is denoted as "CGPI-M", and report its responses to OIL for the first half as well as the second half. Next, in panels (B) and (C) of the same figure, we further decompose CGPI for final goods between consumer goods and capital goods, as their responses are quite different. In panel (B), we use CGPI for consumer goods, restricted to manufacturing products. This means excluding agricultural and mining products, though their shares in consumer goods are quite limited (electricity, gas, and water are excluded from the beginning). We do this for the sake of comparison with CPI, which will appear in panel (D). This series is called "CGPI-C(M)" ("M" for manufacturing). ${ }^{6}$ In panel (C),

6. The 1975 base index for CGPI-C(M) is not available, although the CGPI of overall consumption goods (hereafter CGPI-C) is available. The difference is that CGPI-C includes agricultural goods: we do have information on CGPI of those goods, but their weight in CGPI-C is not reported. In order to deal with this problem, we eliminate the effect of agricultural goods prices from CGPI-C, assuming that their weight for the 1975 base index is the same as that in the 1980 base index. 
we use CGPI for capital goods, denoted as "CGPI-K." It is also interesting to compare the results for CGPI with those for CPI, to see how price changes at wholesale levels are reflected in those at retail levels. A direct comparison is difficult, however, as the two cover very different ranges of products. Most notably, CPI includes not only goods but also services. To make the comparison as meaningful as possible, in panel (D) we report results for CPI for manufactured goods, denoted as "CPI-G(M)", and compare the results with those for CGPI-C(M), in panel (B). For CGPI-C(M), CGPI-K, and CPI-G(M), we detected seasonality and influences of consumption tax rate changes. For those variables, we deseasonalize them by the Census X-11 method prior to the estimation, and also include two dummy variables, corresponding to the introduction of the consumption tax rate in April 1989 and the tax rate change in April 1997, in our estimation.

Going through different panels of figure 5.3, we see that the general tendency for declining pass-through applies to those alternative measures of domestic prices as well. We can also see that the pass-through rate tends to decline as we move downstream from CGPI-M to CGPI-C(M) and CGPI-K, with the former being more sensitive to oil price changes than the latter. Comparing panels (B) and (D), we can see that the responses of CGPI$\mathrm{C}(\mathrm{M})$ are smaller than those for CPI-G(M). The result seems quite puzzling, because wholesale prices, which are more "upstream," are expected to be more sensitive to oil price changes than retail prices, which are more "downstream." We shall come back to this issue in the next section.

\subsection{Evidence from TVP-VARs}

\subsubsection{Evidence for Aggregate Prices}

As we have already argued, regular VARs with subsamples are not necessarily helpful in detecting timing and speed of structural changes. In this section, we employ a time varying parameter VARs (TVP-VARs) to overcome these shortcomings. Refer to the appendix at the end of the chapter for the details of the empirical method employed here. Very briefly, our method is an application of the Kalman filter, and only the reduced-form VAR coefficients are allowed to change over time.

In this section, we continue with our study on aggregate domestic prices. As in the previous section, we estimate a series of TVP-VARs with three variables, namely OIL, IPI, and a measure of domestic prices. ${ }^{7}$ In figure 5.4, we show an example in which we use CGPI as the domestic price index. These

7. Both the VAR and the TVP-VAR approaches treat OIL as an endogenous variable. It might be more appropriate to model it as exogenous to the Japanese economy. We tried estimating a TVP-VARX model with OIL, IPI, and CGPI (total), in which OIL is regarded as an exogenous variable. The estimated pass-through rates were virtually the same as the ones reported later. For this reason, in the chapter, we report results from standard TVP-VARs. 


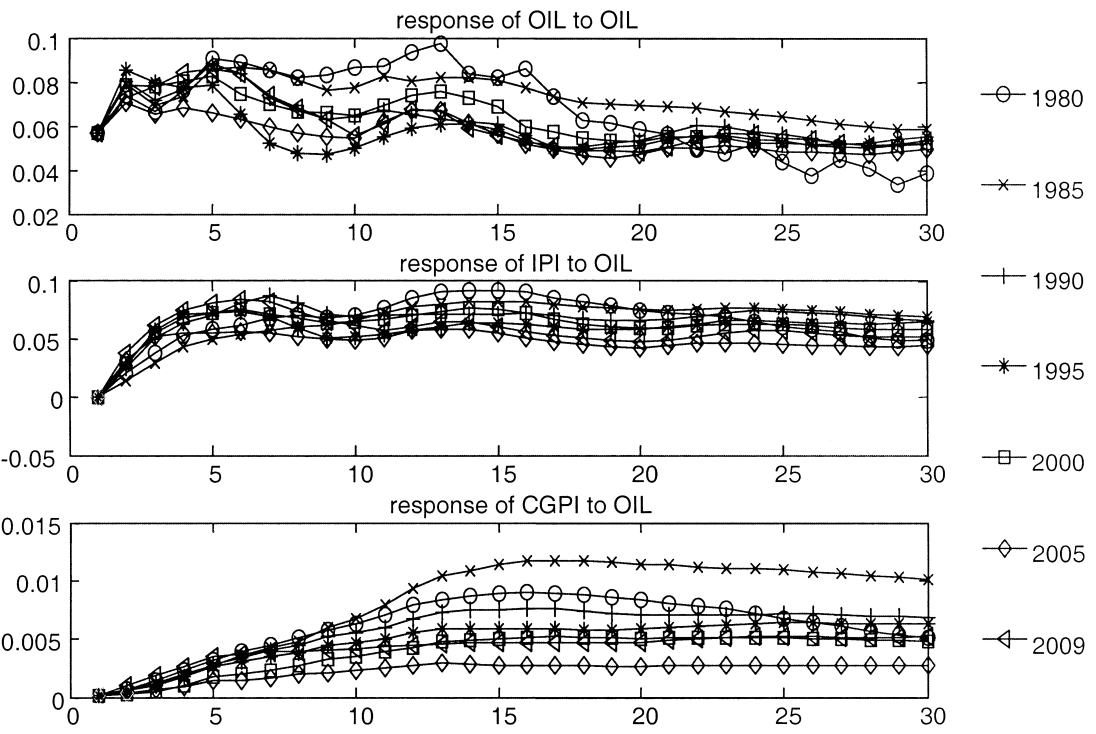

Fig. 5.4 TVP-VAR results for CGPI total: Impulse responses to OIL

are impulse responses, evaluated in January of years 1980, 1985, 1990, 1995, 2000, 2005, and 2009, of each variable to an OIL shock. We can observe that the responses of CGPI shifted upward during the 1980s, moved down sharply at the beginning of the 1990s, and then continued to decline gradually until the mid-2000s. There is a slight shift upward in 2009.

While the regular impulse responses in figure 5.4 are undoubtedly informative, it is difficult to grasp the big picture from here. This is especially so because we wish to compare the responses of the domestic price index (CGPI here) with the "own responses" at each point in time. Next, we try to summarize the vast information provided by the estimation in a little more succinct way. In figure 5.5, we report time series evolution of the estimated "pass-through rates." With respect to an OIL shock, it is defined in the following way:

(Pass-through rate of OIL at time horizon $s$ in period $t$ )

$=($ impulse response of domestic price to an OIL shock at horizon $s$ in period $t$ ) / (impulse response of OIL to an OIL shock at horizon $s$ in period $t$ ).

We present the results in three-dimensional graphs. On the vertical axis, we put the estimated pass-through rate as just defined. On the axis titled "year," we put time period (we show results for January of each year). On the axis labeled "horizon," we put the time horizon; that is, the number of months after the shock hits. Along the time period dimension, we start all the figures 
A

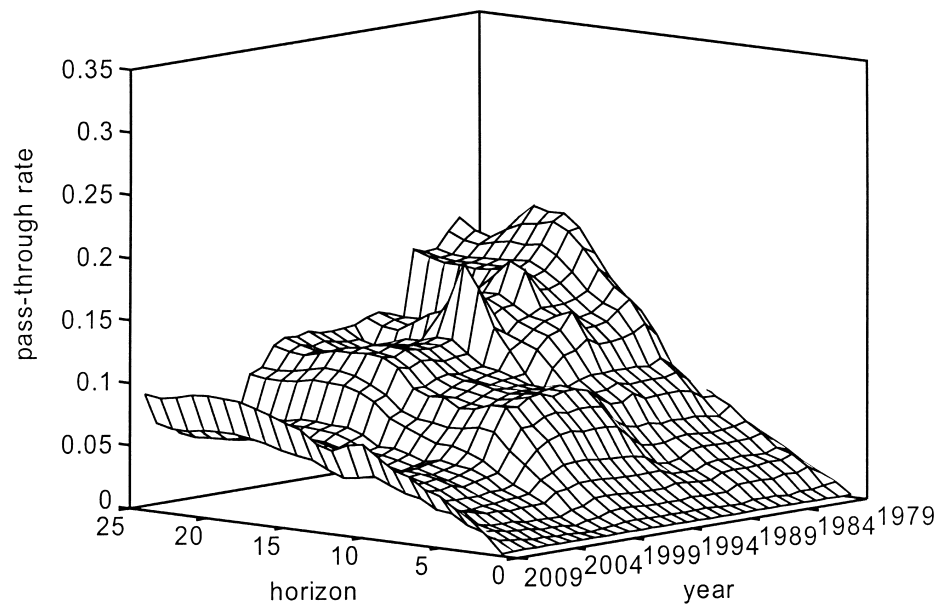

B

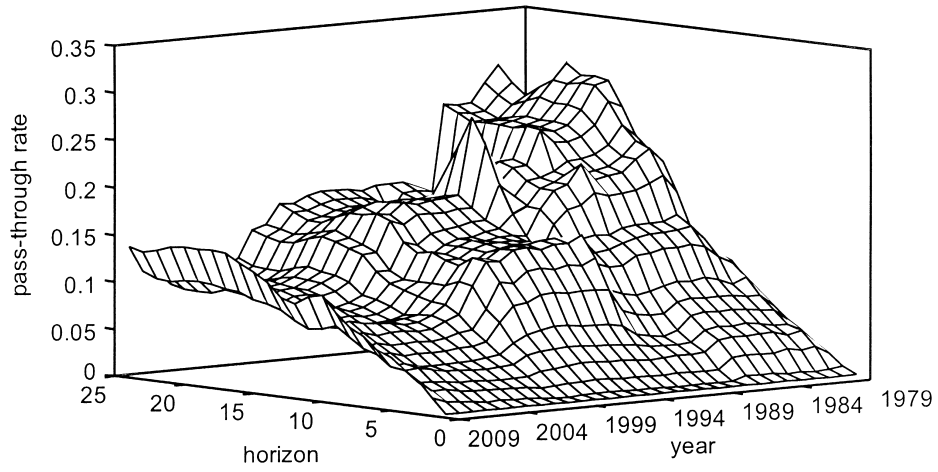

C

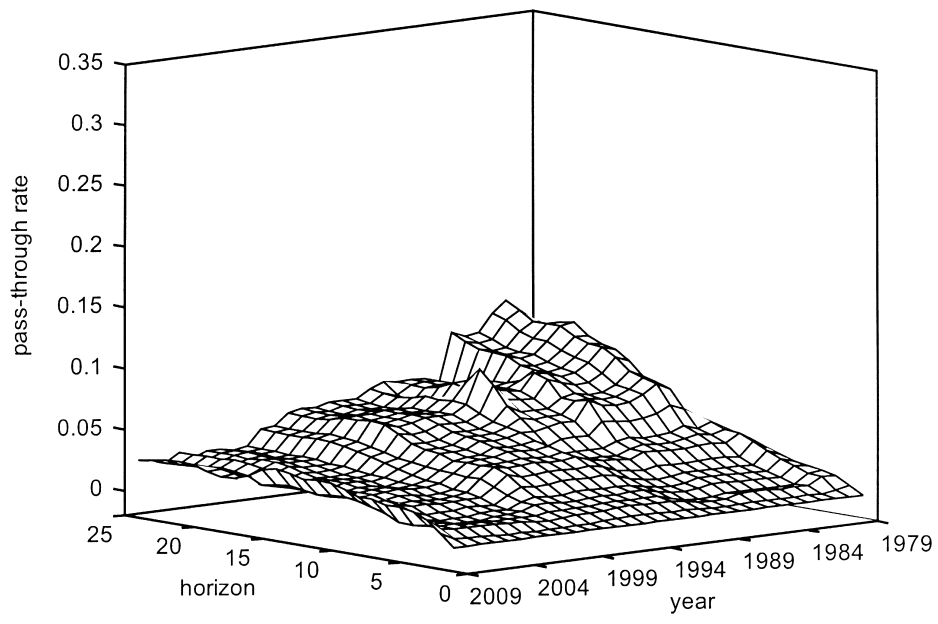

Fig. 5.5 Estimated pass-through rates for aggregate price indices: $A$, CGPI Total; $B$, CGPI-M; $C$, GPI-C(M); $D$, CGPI-K; $E$, CPI-G(M); $F$, Comparison of CGPI-C(M) and CI-G(M) 
D

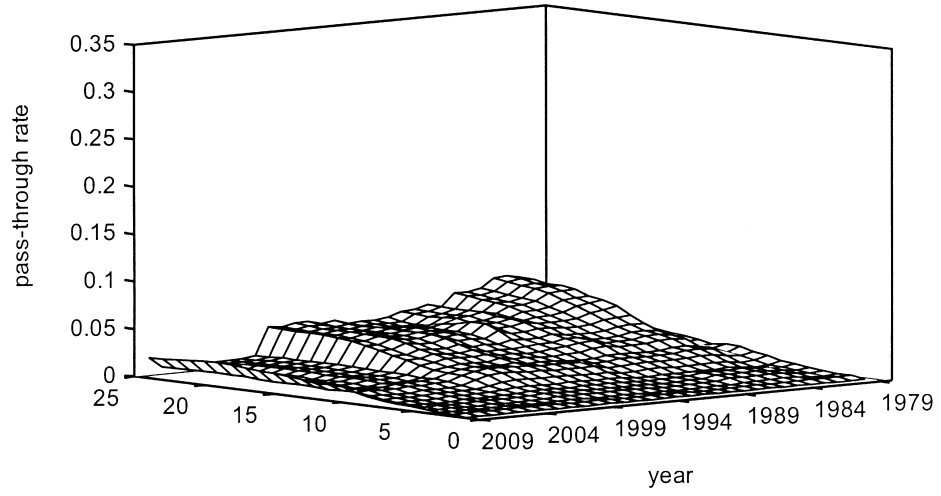

E
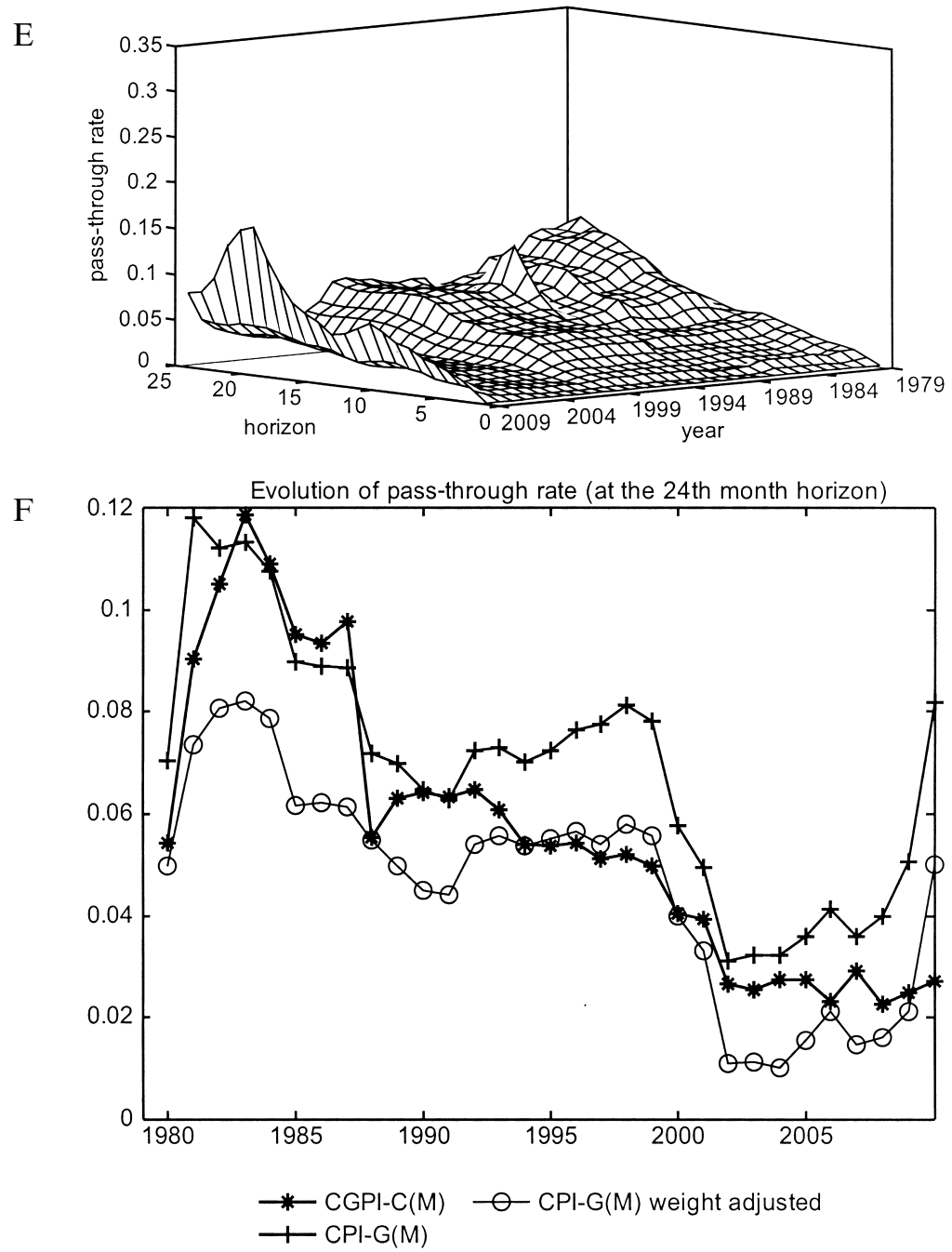

Fig. 5.5 (Cont.) 
from 1979. This is because, in the TVP-VARs, the first few years of estimation results tend to be influenced by initial values set by the researcher.

In figure 5.5, panel (A), we calculate the estimated pass-through rate of OIL to CGPI total. We observe that the pass-through rate goes up at the beginning of the 1980s and comes down gradually but fast in the latter half of the 1980s. It declines further at the end of the 1990s and there is a small increase toward the end of our sample period.

In figure 5.5, panels (B), (C), (D), and (E), we report the pass-through rates for CGPI-M, CGPI-C(M), CGPI-K, and CPI-G(M), from three variable TVP-VARs that incorporate each of those variables in place of CGPI. For the latter three, we deseasonalize them prior to the estimation and regress each of them on the two consumption tax dummies mentioned before, and use the residual in the TVP-VAR. In each of the panels, we find that the basic patterns of the pass-through rate changes over time are similar to those in panel (A). The magnitudes of the pass-through rates among the different CGPI variables are in the order of CGPI-M $>$ CGPI $>$ CGPI-C(M) $>$ CGPI-K.

However, we observe again that the pass-through rate for CPI-G(M) is larger than that of CGPI-C(M) for much of the sample, contrary to our prior expectation. This could be due to different weights attached to durable goods between the two indices: the weight is about 10 percent for CPI-G(M), while it is about 30 percent for CGPI-C(M). As we report in an appendix that is available upon request, when we decompose consumer goods into nondurables and durables, we find that the former is more sensitive to oil prices than the latter. Therefore, the puzzling result could be due to the difference in the composition of the two indices. ${ }^{8}$

In order to examine this hypothesis, we construct a counterfactual series of CPI-G(M) by adjusting the weight for durable goods to be equal to that of CGPI-C(M), and reestimate the three variable TVP-VARs. In figure 5.5, panel $(\mathrm{F})$, we report the evolution of the estimated pass-through rate at the twenty-fourth month horizon derived from this hypothetical price index in the line with circles. We find that, for the most part of the sample, this passthrough rate is lower than that for CGPI-C(M). This result is consistent with our hypothesis. ${ }^{9}$

Although our primary interest in this chapter is in variations of the passthrough rates over time, it is also of interest to see how the levels of the pass-

8. Some argue that these differences are related to a statistical problem that might exist in the Japanese household survey on which the calculation of the CPI's weights is based (Shiratsuka 2005). It is widely recognized, not only in Japan, that the weight of household durables consumption are possibly underreported in household surveys (see ILO 2004, chapter 4).

9. Exceptions are in the latter half of the 1990s and around the year 2009. The difference in the estimated pass-through rates between the two is relatively small for the former period. The difference is larger for the last part of our sample: a possible cause is a deregulation of the retail market for gasoline (refer to the discussion in section 5.3.3). 
through rates in Japan compare with those of other countries, especially in Asia. Jongwanich and Park (2008) conduct VAR analyses of oil price pass-through for various countries in Asia, for the late 1990s and the 2000s, and report their estimated pass-through rates, defined in the same way as in our study. Their estimated rate for Producer Price Index (PPI) is high for Indonesia (around 0.22), Malaysia (0.16), Singapore (0.16), and, to some extent, the People's Republic of China (PRC) (0.14). Korea, Thailand, and the Philippines are intermediate cases with about 0.07 . The rate is much lower for India and Vietnam. In figure 5.5, panel (A), the pass-through rate for CGPI for the same period varies between 0.06 and 0.12 at the twentyfourth month horizon, which places Japan below Indonesia, PRC, and so forth, and closer to Korea and Thailand. This may not be so surprising: Japan, for an industrialized country, has had a high share of manufacturing, especially heavy manufacturing such as automobiles. Even if each plant is energy efficient, it is still possible that the country as a whole is rather energy intensive. Before jumping to a conclusion, however, we would have to further investigate comparability of the data between Japan and those countries.

\subsubsection{Evidence from Plastic}

The previous subsection revealed declining tendencies of pass-through of oil prices to Japanese aggregate prices. This, however, could be due to a mixture of two causes: declines in responsiveness of prices of oil-related products to oil prices, and increases in the shares of nonoil-related products (and also services, in the case of the Consumer Price Index [CPI]). To extract the former effects from the data, we now turn our attention to industry-level price data and focus on products that are very oil intensive. In this subsection, we take up plastic and related products. Distilling crude oil at oil refineries produces "naphtha," among other things, and cracking naphtha in petrochemical steam crackers yields so-called "basic petrochemical products" (ethylene, propylene, benzene, etc.), and they are used to produce various types of "plastic" (polyethylene, polypropylene, etc.). Then plastic is supplied for various purposes, including production of so-called "plastic products" (such as plastic hoses). Here, we study how the pass-through rates of crude oil prices to those products at each of these stages evolved over time.

In figure 5.6, we report results from a series of three-variable TVP-VARs, with crude oil (OIL), IPI of Naphtha, and one of the product-level domestic price indices: that is, CGPI of Naphtha, CGPI of Basic Petrochemical Products, CGPI of Plastic, or CGPI of Plastic Hose. The last one is used as a representative of Plastic Products. ${ }^{10}$ In this subsection, we use IPI of Naphtha in place of crude oil: this is because domestic prices of naphtha are

10. It was difficult to find many CGPI series for plastic products that go back all the way to the year 1975: we could identify only four. We use Plastic Hose as a representative example. 
A

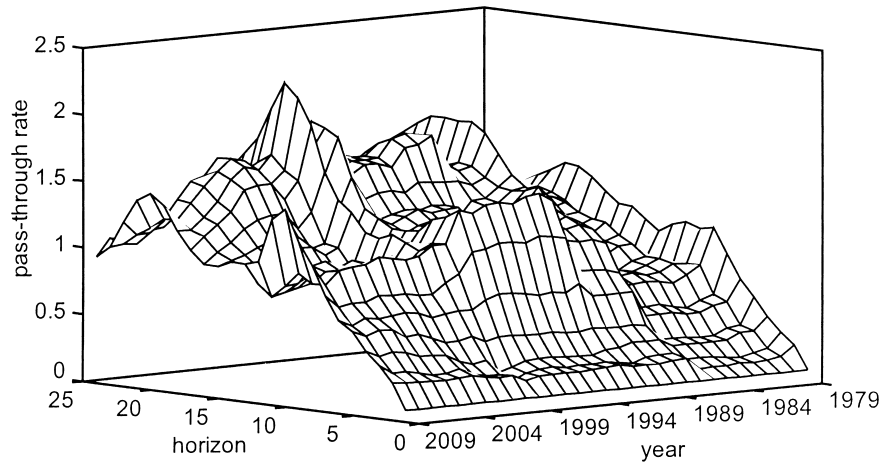

B

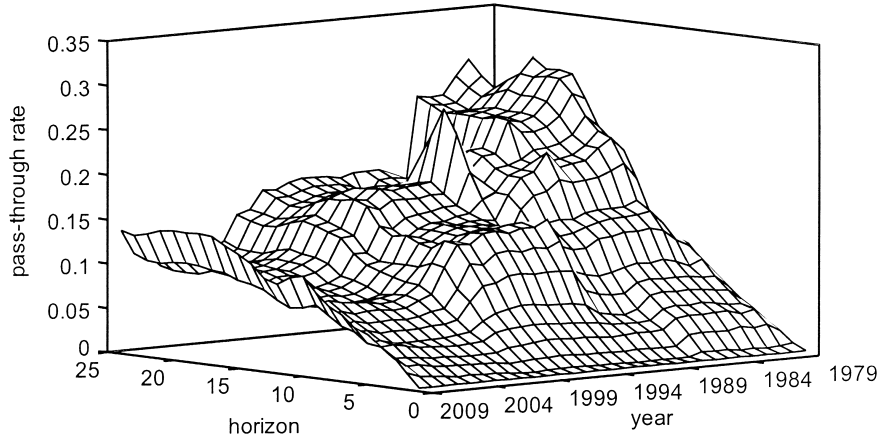

$\mathrm{C}$

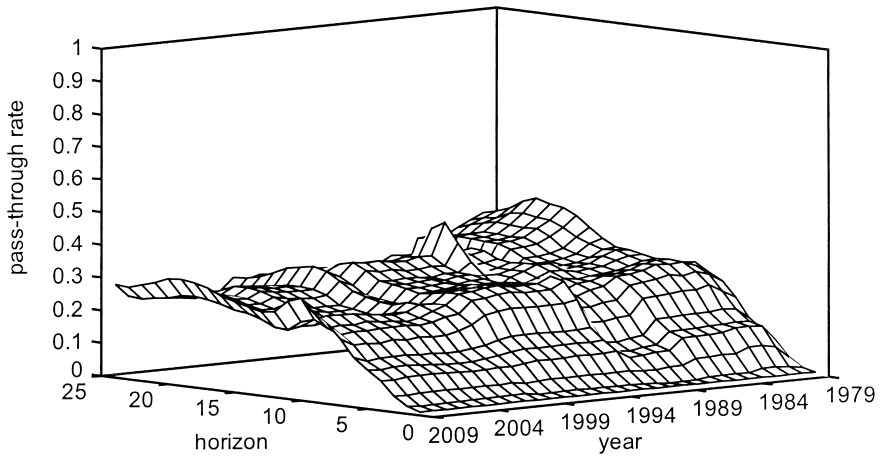

$\mathrm{D}$

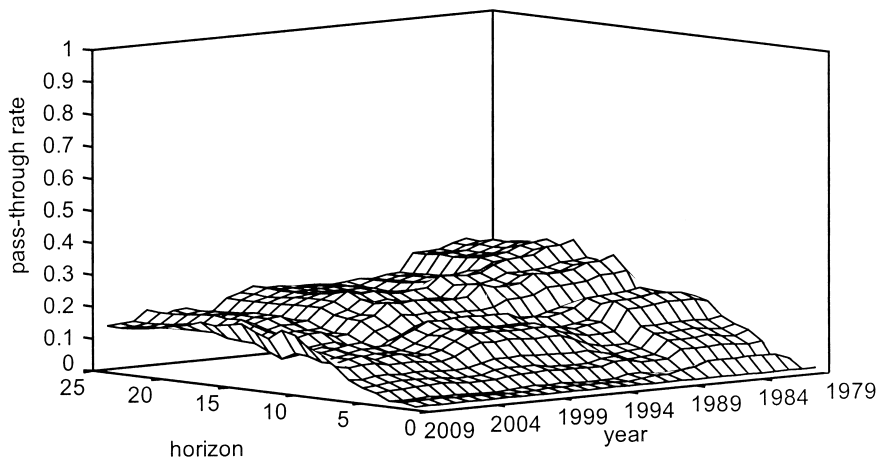

Fig. 5.6 Estimated pass-through rates for plastic and related products: $A$, Naphtha (CGPI); B, Petrochemical (CGPI); $C$, Plastic (CGPI); D, Plastic Hose (CGPI) 
determined in reference to prices of imported naphtha. ${ }^{11}$ First, note that, as we move down the panels - that is, as we move toward downstream of production stages - the estimated pass-through rate tends to decline, as one would expect. Next, we see the same general pattern that we saw in the aggregate prices: the pass-through rate increases sharply at the beginning of the 1980s, declines in the latter half of the 1980s, again toward the end of the 1990s, and we see slight increases in some cases toward the end of the sample period. The only exception to this general tendency is naphtha. The estimated pass-through rate seems too high, often exceeding 1 (note that the scale of the vertical axis is different for panel (A) only), and the pattern of the time variation is unclear. This could be because, as mentioned earlier, prices of domestically-produced naphtha are determined by some nonmarket rule.

\subsubsection{Evidence from Gasoline}

Next, we turn to the case of gasoline. Again, we estimate a three-variable TVP-VAR, with OIL, IPI of crude oil, and CPI of gasoline. To control for disruptive effects of a temporary reduction and a subsequent increase in the gasoline tax rate in 2008, we first regress log differences of gasoline prices on the March 2008 dummy and the April 2008 dummy. Then the residuals are included in our TVP-VAR estimation. We report the estimated pass-through rates in figure 5.7, panel (A). We observe that the level of the pass-through rate is lower compared with, for example, naphtha. Its tendency to decline over time, before starting to increase again in the late 2000s, is similar to the previous results.

As gasoline is one of few oil-intensive items that appear in both CGPI and CPI, it is of interest to study how the results differ between the two. In figure 5.7, panel (B), we compare the evolution of their estimated pass-through rates at the twenty-fourth month horizon. As expected, the pass-through rate is higher for CGPI of gasoline than its CPI counterpart for much of the sample. However, somewhat surprisingly, toward the end of the sample, the order is reversed. One possible cause of this is the deregulation of the retail market for gasoline. According to Japan Fair Trade Commission (2004), a series of deregulation put gasoline stations under strong competitive pressures. This might have made retail gasoline prices sensitive to various factors affecting oil prices. On the other hand, the supplier side of gasoline to those stations remains oligopolistic. ${ }^{12}$

11. To be more precise, this custom started formally in 1982, when the Ministry of International Trade and Industry decided that domestic prices of naphtha should be determined by adding certain margin to prices of imported naphtha, and that the price should be revised every quarter (rather than monthly).

12. Some participants at the Twentieth East Asian Seminar on Economics suggested using the gasoline tax reduction in March 2008 (and the subsequent tax hike in the following month) as a natural experiment to study how cost changes are transmitted to wholesale and retail prices. We think this incident was quite different in its nature from most of the oil price increases in history in one important aspect: the tax reduction was fully expected to be very temporary 
A

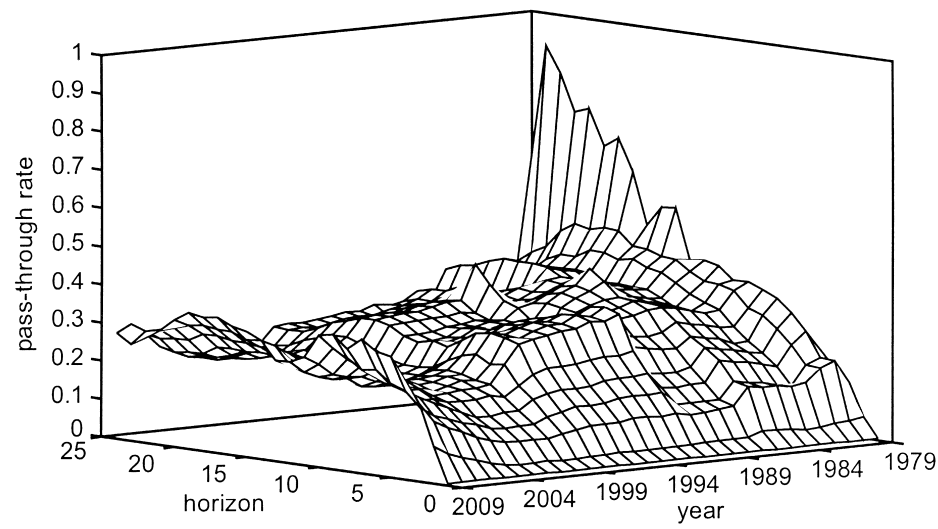

B

Evolution of pass-through rate (at the 24th month horizon)

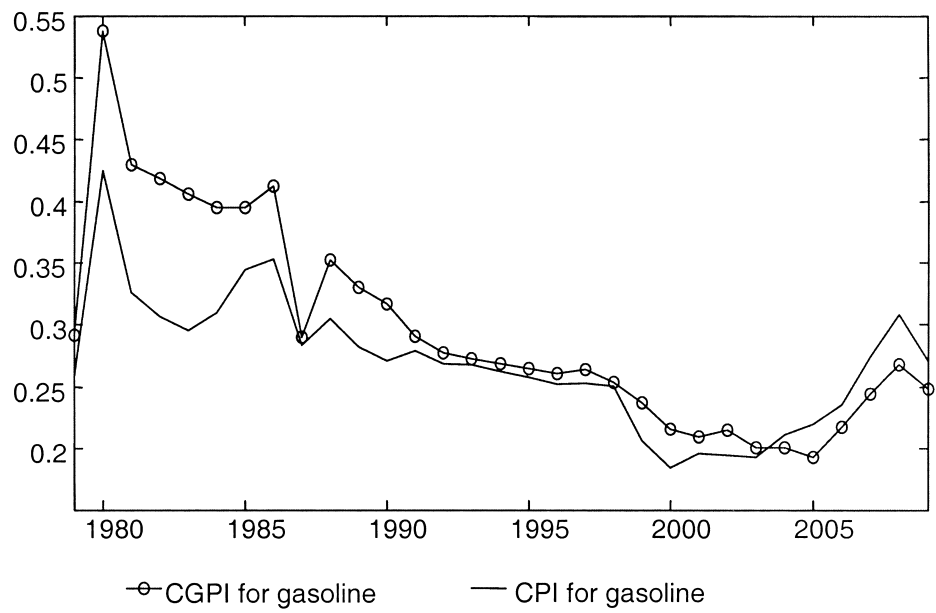

Fig. 5.7 Estimated pass-through rate for gasoline: $A$, Estimated pass-through for Gasoline (CPI); B, Estimated pass-through rates, Gasoline (CGPI) and Gasoline (CPI)

\subsubsection{Evidence from Electricity}

Finally, we turn to the case of electricity. In this case, we estimate a threevariable TVP-VAR: with OIL; IPI of "crude oil, coal, and natural gas," and CGPI of electric power. We include natural gas, and so forth, in our definition of IPI here, because even thermal power plants use not only oil but also

from the beginning. As a consequence, this policy induced tremendous intertemporal substitution of gasoline usage, both before and after the tax rate changes. We think it is difficult to make inference about the effects of oil price changes, which are typically more persistent, by studying this event. 


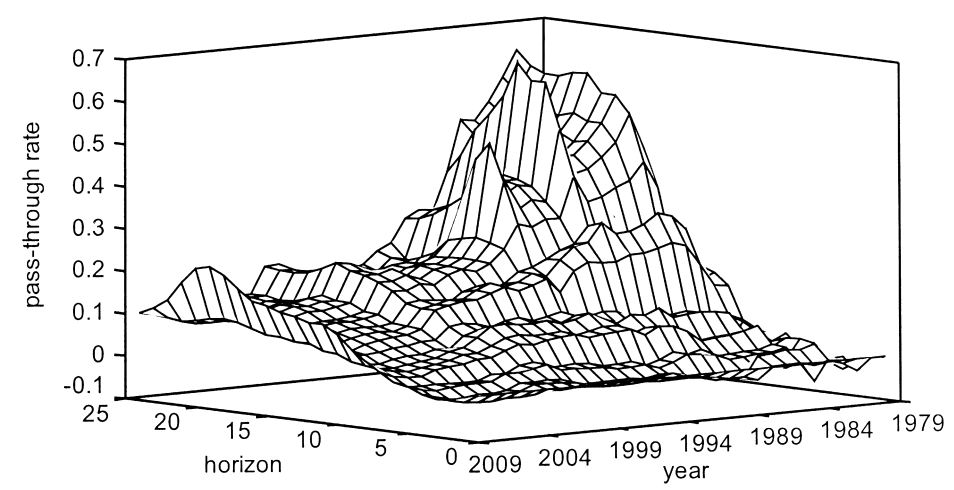

Fig. 5.8 Estimated pass-through rate for electricity

coal and natural gas. ${ }^{13}$ The CGPI of electric power is deseasonalized by the Census X-11 Method. We report the estimated pass-through rates in figure 5.8. We can observe continuous declines in the pass-through rate, starting in the early 1980s and lasting throughout much of the sample period, until it starts to increase again toward the end of the sample.

To summarize this section, we have seen that the declines in the passthrough rates at the aggregate level are not simply a result of shrinking shares of oil-related products. Even at the level of those products, we can find declines in the pass-through rates. In the next section, we study implications from the input-output tables to see if this can be explained from changes in the cost structure of oil-related production.

\subsection{Cost Structure and Pass-Through Rates: What Do the Input-Output Tables Predict? The 1980 to 2000 Period}

\subsubsection{Data and Methodology}

In Japan, frequent changes in rules and methodology (such as classification of goods and services) make a long-run comparison of input-output structure difficult. Fortunately, the Research Institute for Economy, Trade, and Industry (RIETI) provide detailed input-output tables for years 1980, $1985,1990,1995$, and 2000 that are directly comparable between each other (see http://www.rieti.go.jp/jp/database/d01.html [in Japanese only]). They provide tables in both nominal units and real (constant 1995 price) units. Each of the tables contains 511 rows (industries that provide inputs) and 398 columns (industries that use those inputs). Most notably, "crude oil"

13. In fact, oil has come to play a relatively minor role. We shall discuss this matter further in the next section. 
appears as a single row item (though, on the column side, it is combined with natural gas). Also, different types of Petroleum Products, such as "gasoline," "naphtha," "fuel oil A," and "fuel oil B\&C," all appear as separate items on the row side (though they are all combined into one on the column side). This is important, as different types of Petroleum Products receive very different tax treatments. We make suitable assumptions to expand the tables into matrices of dimensions 511 times 511. ${ }^{14}$

Naturally, we are also interested in the period after 2000. The next section employs more recent I-O tables, which are much smaller than the ones just explained (due to limited data availability), to study the 2000s.

The I-O tables can be used to derive predictions on a percentage response of the average price of products of a certain sector when the price of imported goods (say, of another sector) increases by 1 percent. The input-output analysis with $N$ sectors (with trade) has the following basic structure:

$$
\mathbf{x}=A \mathbf{x}+\mathbf{d}+\mathbf{e}-M(A \mathbf{x}+d),
$$

where $\mathbf{x}$ is the vector of output $(N \times 1), A$ is the input coefficient matrix, $\mathbf{d}$ is the vector of domestic final demand $(N \times 1)$, $\mathbf{e}$ is the vector of exports $(N$ $\times 1$ ), and $M$ is the matrix of import coefficients. The matrix $M$ is a diagonal matrix whose $i$ th diagonal element is the ratio of the imports of the $i$ th sector to the sum of intermediate inputs from the $i$ th sector to all the sectors plus the domestic final demand to this sector's output. From here, it is possible to derive the following pricing equation:

$$
\Delta \mathbf{p}=\left[(I-(I-M) A)^{-1}\right]^{\prime} \cdot A^{\prime} M^{\prime} \cdot \Delta \mathbf{p}^{m},
$$

where $\Delta \mathbf{p}$ is the vector of the rate of domestic price change in each sector and $\Delta \mathbf{p}^{m}$ is the vector of the rate of price change of imported goods in each sector. For example, suppose that the crude oil sector is the $J$ th sector and that we wish to study the impact of 1 percentage increase in imported crude oil price. Then we set the $J$ th element of the vector $\Delta \mathbf{p}^{m}$ to be 1 and all the other elements to be 0 . Then each element of $\Delta \mathbf{p}$ would indicate the predicted percentage increase in the domestic prices of goods in each sector, under the assumption of flexible prices (complete pass-through at

14. The numbers of columns and rows do not coincide basically because certain row industries are combined into single column industries. In such cases, in principle, we assume that each row industry that belongs to the same column industry group has the same input structure. There are only very minor exceptions in which the correspondence between the row industries and the column industries is not perfect. For Petroleum Products, it is important to consider the fact that different types of products are subject to very different tax schemes. For this reason, we take the following approach. From the input-output table for each year, we obtain the total amount of indirect taxes paid by the whole Petroleum Products sector. From tax revenue statistics of the Ministry of Finance, we obtain the shares of taxes imposed on each type of Petroleum Product. We allocate indirect taxes to each of the subsectors according to those shares. The rest of the cost structure is assumed to be the same across those subsectors. We consider this to be a reasonable assumption, as all of those products are by-products of a single distillation process. 
each production stage) and zero substitution. In essence, the previous equation provides a way to compute "oil contents" of the cost of production for each sector, which takes into account the complex input-output structure of the economy.

In this chapter, we utilize both nominal and real I-O tables to derive those predictions. The current prices table will predict the impact of an increase in oil prices given the current cost structure of each industry. The constant price table, on the other hand, will give a hypothetical prediction on what would happen if only the real cost structure changed between the current year and the benchmark year (due to, for example, substitution between oil and other types of materials), while maintaining the same relative price structure. It turns out that differences in predictions from those two types of tables are quite informative.

\subsubsection{Plastic, 1980 to 2000}

We start with product level analysis here. Figure 5.9, panel (A), uses the nominal I-O tables to derive the predicted responses of Naphtha; Basic Petrochemical Products (ethylene, propylene, benzene, etc.); Thermoplastic Resin (a type of plastic: polyethylene, polypropylene, etc.); and Plastic Products. Solid lines with cubes show the predicted percentage responses of those prices when the price of imported crude oil increases by 1 percent. Dashed lines with triangles show the predicted responses when imported prices of both crude oil and petroleum products increase by 1 percent, simultaneously. This calculation is necessary because currently Japan imports much of naphtha it needs from abroad (which was not the case in 1980). Solid lines with circles show what happens when prices of all the imported goods increase simultaneously by 1 percent. Figure 5.9, panel (B), performs an analogous study using the real I-O tables (1995 constant prices).

The contrast between panels (A) and (B) is striking. While the nominal I-O table predicts sharp declines in the price responsiveness over time, the real I-O table does not predict any systematic tendency. The fact that the real I-O table does not predict much decline suggests that there was not much of a real substitution away from the use of oil during this period. We had expected a decline in the importance of oil, at the very least in the comparative sense, as we had originally thought the importance of services such as distribution and finance would have increased over time: apparently, that did not happen. Yet the nominal I-O table tells a very different story. The difference comes from the fact that, during this period, there were substantial declines in prices of imported oil, naphtha, and other imports. To summarize, although there was very little substitution between quantities of different types of input, the relative importance of oil still declined substantially, basically because it became cheaper. As the lower price of oil reduced its share in overall nominal production costs, prices of those products became much less responsive to fluctuations in oil prices. 

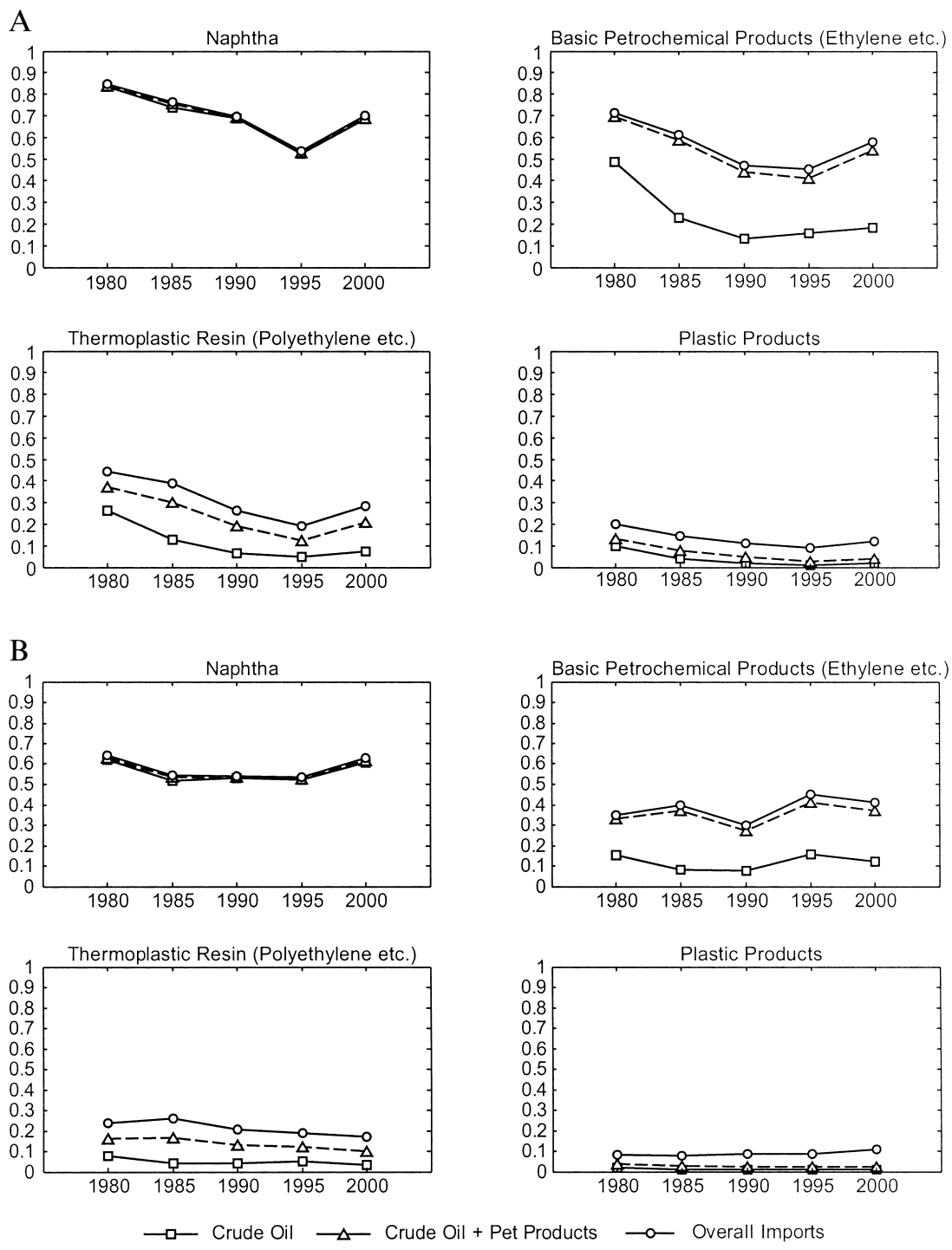

Fig. 5.9 Predicted responses of plastic and related products to OIL (etc.): $A$, Predictions from nominal I-O tables; $B$, Predictions from real I-O tables (1995 constant prices)

How do these predictions in figure 5.9, panel(A), compare with the actual estimation results in figure 5.6? Comparing the two panel by panel (looking at the long-run estimated pass-through rates at the twenty-four months horizon in each panel of figure 5.6), we learn that the cost-related factors that appear in figure 5.9, panel (A), are enough (in some cases, more than 
enough) to explain the declines in the estimated pass-through rates. Our conclusion for these sectors is that the pass-through rates of oil declined because oil became cheaper and thus became less important in overall costs for those sectors.

\subsubsection{Gasoline, 1980 to 2000}

Studying the case of gasoline in Japan requires a caution, as it is subject to heavy taxation. ${ }^{15}$ What is important is that those taxes are per-unit taxes (or specific duties) as opposed to ad valorem taxes. Taxes therefore do not go up when oil prices increase. In the period of high oil prices, the share of those taxes in overall gasoline prices is relatively low. Gasoline prices will move nearly one-for-one with oil prices. When oil prices are lower, the share of taxes - the portion that does not respond to oil price fluctuations - in overall gasoline prices is higher. Gasoline prices are thus expected to be less responsive to oil price changes. Pass-through rates of oil prices are thus expected to change endogenously with the level of oil prices. This could at least partially explain the declining pass-through rate we saw in figure 5.7.

In fact, we estimate that, as of 1980 , indirect taxes were equal to about 29.6 percent of total output value of gasoline. In 2000, this ratio was up to as high as 53.8 percent.

To study the magnitude of this effect, in figure 5.10, panel (A), we first compute predicted response of gasoline prices to oil prices from the nominal I-O tables, under the actual cost structure (line with cubes). Note that those predictions are fairly close to the actual estimated pass-through rates (reported in figure 5.7) for the medium and long runs. Next, we redo the calculation under the counterfactual assumption that the indirect taxes did not exist (or the taxes move proportionately with prices), and the results appear in the line with triangles. Lastly, we redo the analysis by assuming that not only domestic taxes but also tariffs did not exist (or they also move proportionately with prices), and the results appear in the lines with circles.

Comparing those lines reveals that the presence of those taxes is greatly mitigating the responsiveness of gasoline prices to oil prices. More importantly, the presence of those taxes made the responsiveness to decline substantially between 1980 and 2000 . Without those taxes and tariffs, the responsiveness would have decreased by relatively small percentages. Figure 5.10 , panel (B), does analogous calculation based on the real I-O table. We see that, without the effects of nominal price levels and taxes and tariffs, the responsiveness would have remained nearly constant, and high. We conclude that the declining pass-through rates in figure 5.7 could possibly be explained entirely by those two effects.

15. Also, diesel and jet fuel are heavily taxed in Japan. On the other hand, naphtha and heavy fuel oil are, relatively speaking, lightly taxed. This necessitates careful treatment of indirect taxes that we explained in the previous section. 
A

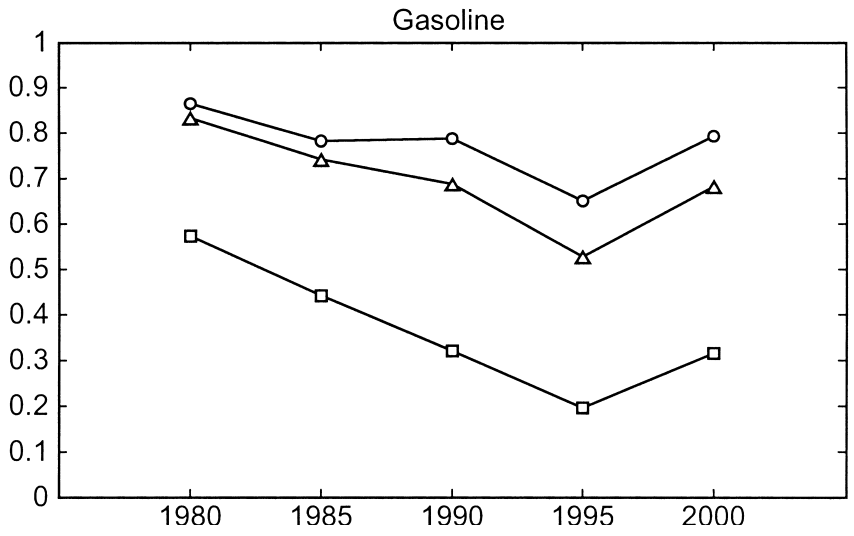

B

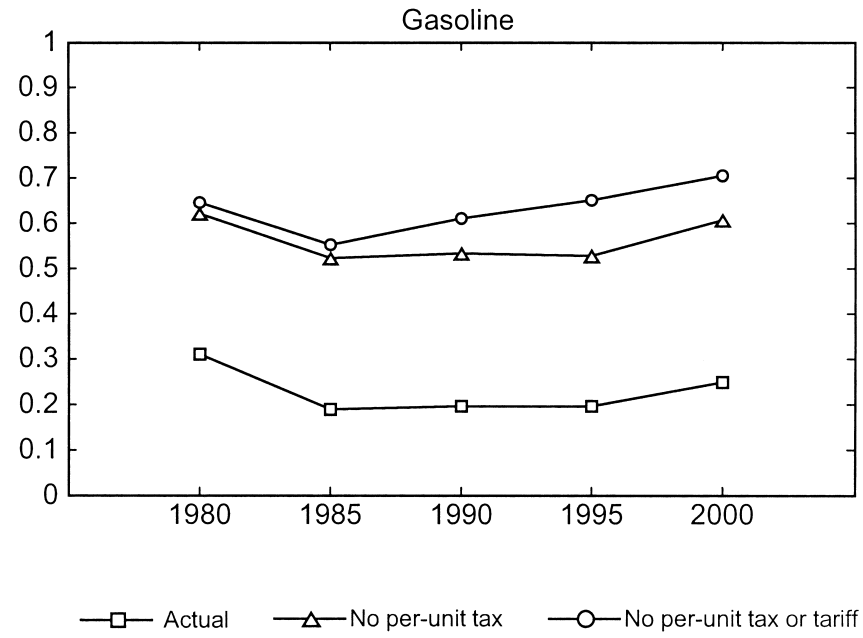

Fig. 5.10 Predicted responses of gasoline to OIL: $A$, Predictions from nominal I-O tables; $B$, Predictions from real I-O tables (1995 constant prices)

\subsubsection{More on the Importance of Taxes:}

Diesel and "Type A Fuel," 1980 to 2000

To further investigate the importance of the presence of taxes in passthrough of oil prices, we next consider two types of petroleum products, diesel and so-called "type A fuel." Those two are almost identical in their physical nature. The difference is that diesel is heavily taxed. From the I-O tables, we estimate that the ratio of indirect taxes to diesel production was 20.0 percent for 1980 and 40.6 percent in 2000 . On the other hand, type A fuel is very lightly taxed. As a consequence, usage of this type of fuel is restricted mainly to agriculture and fishery. According to our argument in the previous subsection, we should observe higher pass-through rates for type A fuel. 


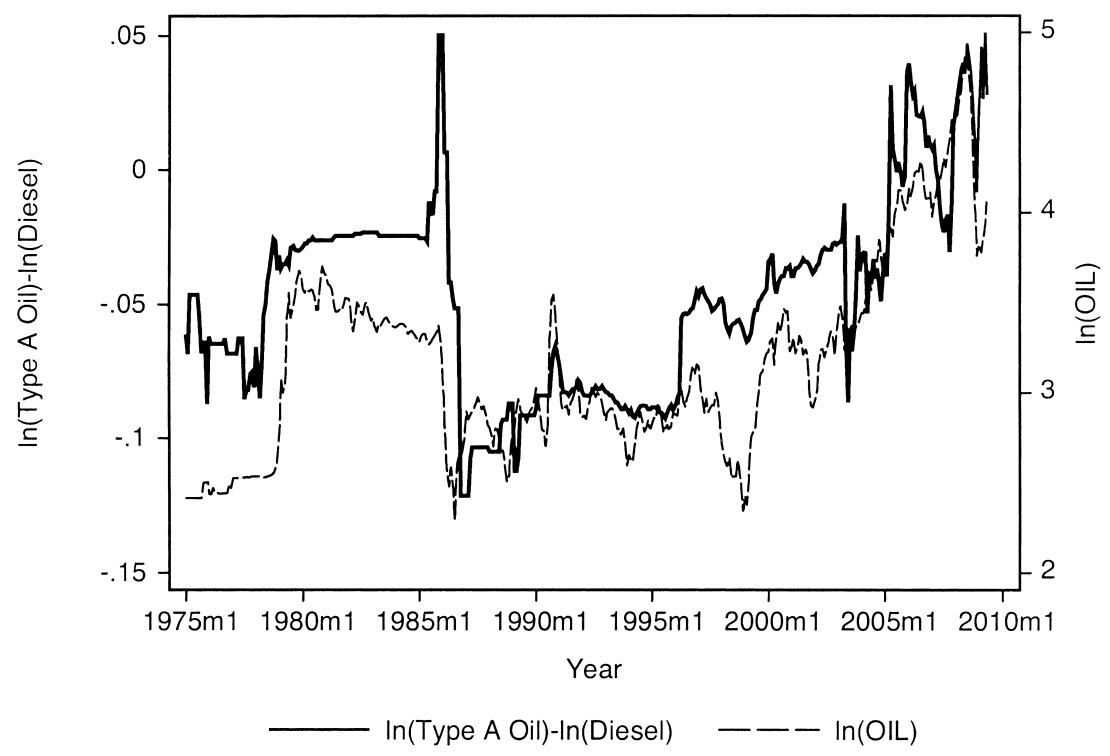

Fig. 5.11 Evolution of price differentials between type A fuel and diesel (solid line) and oil prices (dashed line), all the prices are in logs

In figure 5.11, we show the difference between prices of those two types of products (in logarithms), along with crude oil prices. It is evident that the two are highly correlated. This is an indication that type A fuel responds more strongly to fluctuations in oil prices; that is, their pass-through rates are higher.

Next, we estimate regular three variable VARs with OIL, IPI (of crude oil), and either type A fuel or diesel. Figure 5.12 shows impulse responses of type A fuel (solid line) and diesel (dashed line) to OIL for the first half of the sample (left panels) and the second half (right panels). We confirm our hypothesis that, as type A fuel is lightly taxed, it tends to be more responsive to oil price changes.

\subsubsection{Electricity, 1980 to 2000}

We next turn to the case of electricity. There are two electricity-related entries in the I-O table, namely electricity for business uses and self uses. We derive the predicted responses for both of them, and the results are shown in figure 5.13, panel (A), for the nominal table and panel (B) for the real table. We study the case in which only crude oil prices increase (solid lines with cubes), the case in which oil and natural gas prices increase simultaneously by 1 percent (dashed lines with triangles), and the case in which prices of all the imported goods increase at the same time (solid lines with circles). The nominal tables predict substantial declines in pass-through rates of oil. The estimated pass-through rates in figure 5.8 are close to predictions that 

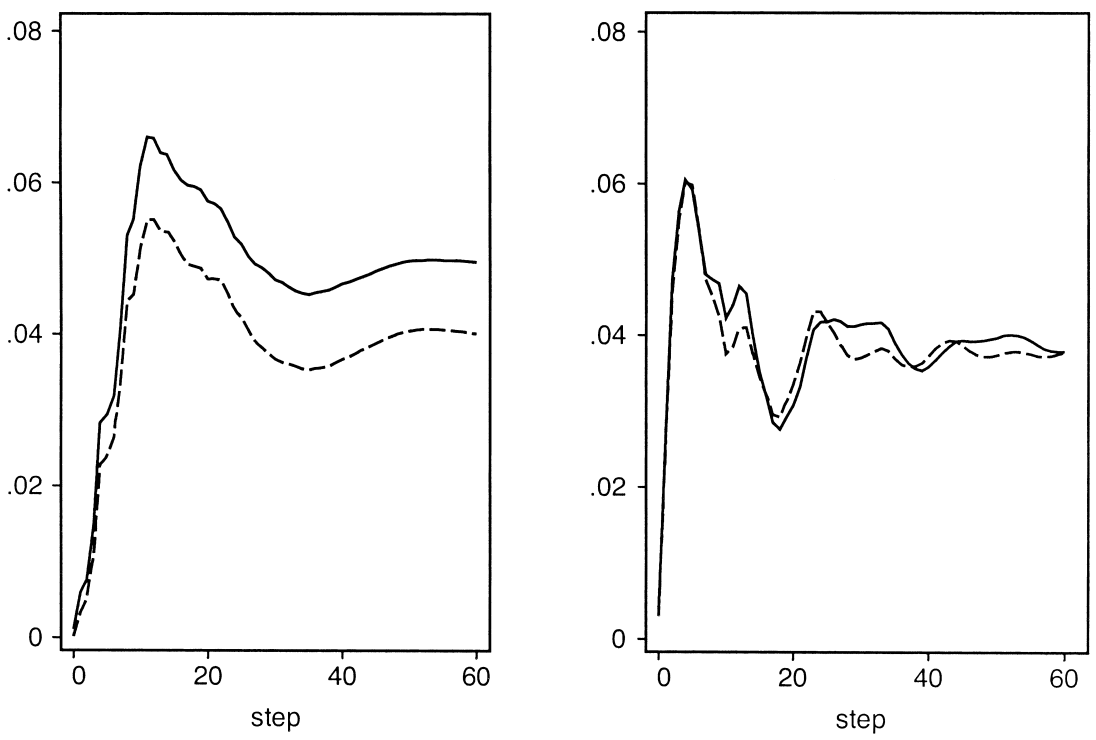

Fig. 5.12 Impulse responses to OIL of type A fuel (solid lines) and diesel (dashed lines), first half (left) and second half (right)

appear in the solid line with circles in the electricity for self use case. What is noteworthy about this sector is that, even in the predictions from the real tables, we observe some declines in the predicted responsiveness, though the declines are much smaller compared with the predictions from the nominal tables. The decline is most evident for "crude oil" in the "electricity for self use" case. It is also likely that increasing use of imported coal and construction of nuclear power plants have contributed to the general tendency. Evidently, some part of this decline, since 1990, is the emergence of natural gas as an alternative to using oil. Hence, we conclude that, for this sector, real substitution played a minor but nonnegligible role.

Another feature of the electricity industry is that prices were under strict regulations previously, but a series of deregulation took place during our sample period. This would have contributed to increase the pass-through rate. But such an increase does not seem to show up in a noticeable manner either in figure 5.8 or in 5.12 .

\subsubsection{Overall Consumer Goods Prices, 1980 to 2000}

Through the I-O analysis in this section, we have found some important elements that could explain declining pass-through of oil prices. The most notable factor has been the relative price factor, or the relative price of oil itself. Input substitution showed up as a minor (but nonnegligible) factor for electricity. Also, the analysis for gasoline has pointed out importance of the 

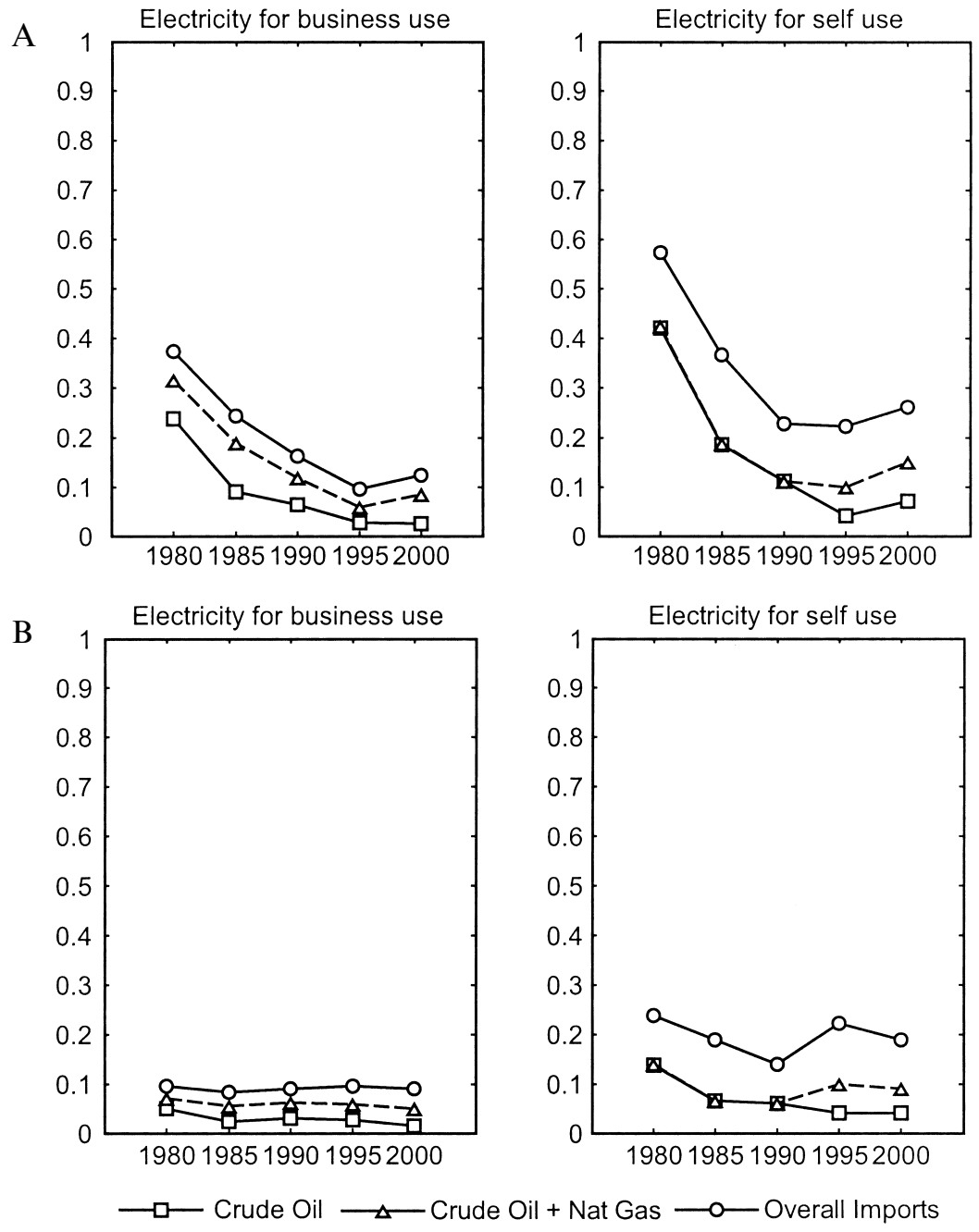

Fig. 5.13 Predicted responses of electricity to OIL (etc.): $A$, Predictions from nominal I-O tables; $B$, Predictions from real I-O tables (1995 constant prices)

tax structure. Are they important in accounting for declines in pass-through rates in overall prices as well? To answer this question, we apply the same procedure we have employed so far to all the sectors in manufacturing simultaneously. Then we take weighted averages of their predicted responses, where the weights are based on the amount consumed by households. This is an effort to derive predictions about how manufactured consumer goods prices, or CGPI-C(M), would respond to oil prices. The results are in figure 5.14. Panel (A) uses the nominal tables. Panel (B) uses the real tables. Panel 
A

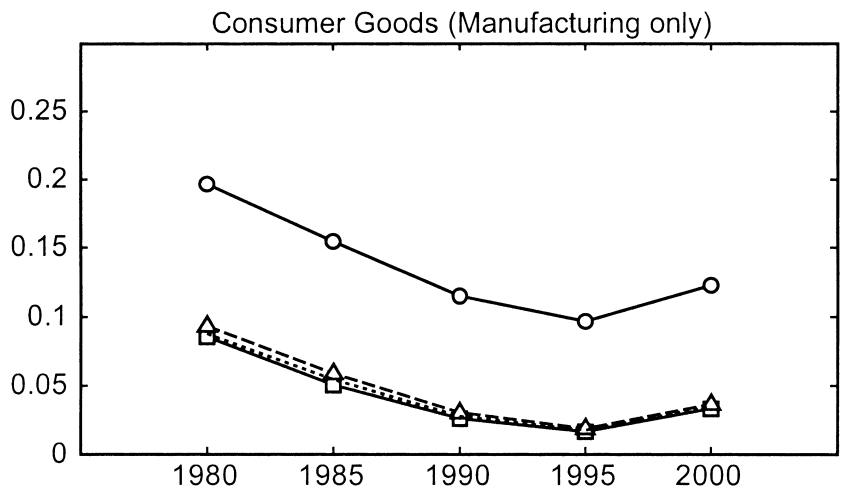

B

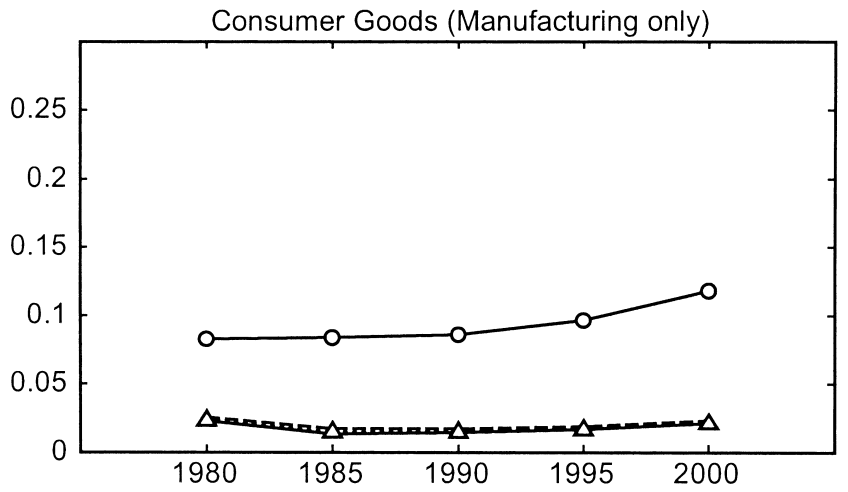

C

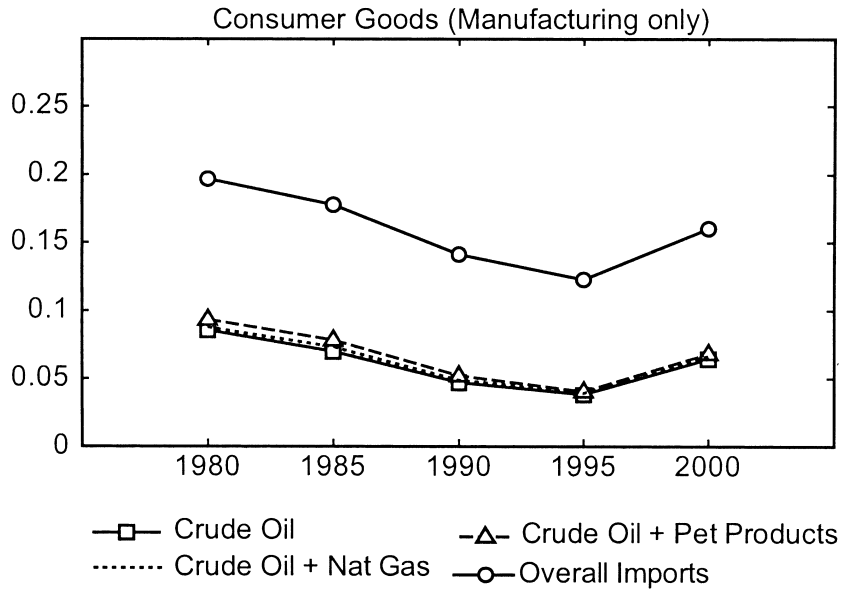

Fig. 5.14 Predicted responses of manufactured consumer goods prices to OIL (etc.): $A$, Predictions from nominal I-O tables; $B$, Predictions from real I-O tables; $C$, Predictions from nominal I-O tables with no taxes or tariffs on petroleum products 
Comparisons between TVP-VAR estimates and predictions from I-O tables for consumer goods

\begin{tabular}{|c|c|c|c|c|}
\hline & $\begin{array}{l}\text { TVP-VAR } \\
\text { estimates, } \\
\text { 12th month } \\
(1982-2002)\end{array}$ & $\begin{array}{l}\text { TVP-VAR } \\
\text { estimates, } \\
\text { 24th month } \\
(1982-2002)\end{array}$ & $\begin{array}{l}\text { Prediction } \\
\text { from } \\
\text { NOMINAL } \\
\text { I-O tables } \\
(1980-2000)\end{array}$ & $\begin{array}{c}\text { Prediction } \\
\text { from REAL } \\
\text { I-O tables } \\
(1980-2000)\end{array}$ \\
\hline $\begin{array}{r}\text { Percentage decline in } \\
\text { pass-through rates }\end{array}$ & $-69.0 \%$ & $-78.6 \%$ & $-61.3 \%$ & $-7.1 \%$ \\
\hline
\end{tabular}

Note: Manufacturing only: percentage declines in estimated versus predicted pass-through rates to oil prices.

(C) uses the nominal tables, under the hypothetical assumption that there are no per-unit taxes or tariffs on Petroleum Products (such as gasoline, diesel, and jet fuel).

Predictions from panel (A) fit very well with the evolution of the estimated pass-through rates for CGPI-C(M) that appears in figure 5.5, panel (A). This leads us to suspect that changing cost structure could go a long way toward explaining observed declines in pass-through between 1980 and 2000. Comparison between panels (A) and (B), on the other hand, seems to indicate that the real side story plays only a minor role in the structural change that lowered pass-through during this period: we observe only slight declines in the predicted responsiveness to imported oil, petroleum products (basically naphtha), and natural gas. This indicates that, once again, the main factor behind the change was the relative price factor: as oil became cheaper, it became less relevant in the cost structure.

To give more formal and quantitative support to the aforementioned impressions, in table 5.1 we contrast our TVP-VAR estimates for the passthrough rates for CGPI-C(M), which appear in figure 5.5, panel (C), with predictions from both nominal and real I-O tables for manufactured consumer goods that appear in figure 5.13, panels (A) and (B). All the numbers are percentage declines in pass-through rates, either estimated or predicted. The first column indicates that the estimated pass-through rate at the twelfth month horizon declined, between January 1982 (its peak in figure 5.5, panel (C)) and 2002 (its bottom), by 69 percent. Likewise, the second column indicates that the estimates at the twenty-fourth month horizon declined by 78.6 percent. The third column indicates that the predicted pass-through rate from the nominal I-O table declined, between 1980 and 2000, by 61.3 percent. Hence, changes in cost structure, namely the relative price changes and relative quantity changes combined, can account for between 78 percent and 89 percent of the declines in the estimated pass-through rate, leaving only about 11 percent to 22 percent for the other factors to explain. The fourth column indicates that the predicted pass-through rate from the real I-O table 
declined by just 7.1 percent. Thus, the relative quantity factor played a minor role in this long-term decline in the pass-through rate.

We should acknowledge that our results do not eliminate the possibility that there was some other important factor that contributed to the declining pass-through, whose effect was largely offset by yet another factor that happened to work in the opposite direction. Nevertheless, to be able to support such a view, one would first have to specify what this force that was working in the other direction was, and this is, in our view, not an easy task.

It is also important to note that our results do not entirely deny the importance of the real factor or the relative quantity factor. We have already seen that it was quite important in the electricity sector. Figure 5.13, panel (B), indicates that the relative quantity factor was also important in the period 1980 to 1985: during this short period, the predicted pass-through rate from the real I-O table declines by as much as 40.7 percent, and this accounts for all of the decline in the prediction from the nominal I-O table. This suggests that, in reaction to the sudden increase in oil prices in the early 1980s, Japanese households and firms shifted away from oil-intensive products and inputs, temporarily. After oil prices declined in the late 1980s, however, there was some unwinding of this effect. As a result, the relative quantity effect does not contribute much to the long-run trend of declining pass-through.

Finally, panel (C) of figure 5.13 is similar to panel (A), but the decline in the predicted responsiveness to oil prices for the 1990s is milder. In fact, between 1980 and 2000, it declines by only 24.5 percent, compared to 61.3 percent in table 5.1. This confirms the importance of the presence of taxes that are imposed per volume.

\subsection{Predictions from the I-O Tables, 2000 to 2007}

In this section, we shift our focus to the 2000s, especially toward the end of this period. At the time of this writing, detailed input-output tables were available only up to the year 2006, which is not sufficient for our purpose. We have decided to employ basic input-output tables provided by the Ministry of Economy, Trade, and Industry, with only seventy-three sectors, which were available for years 2000 and 2003 to 2007. In these tables, "crude oil" is no longer a separate sector but is combined with natural gas. Also, all the Petroleum Products subsectors are merged into one. We expand them by making suitable assumptions to decompose a single Petroleum Products sector into nine subsectors. ${ }^{16}$ As in the previous section, we compute

16. On the row side, for years 2004 to 2006 , we have information from detailed I-O tables with 511 row sectors, and we can directly utilize information provided by these tables to decompose a single row into nine separate ones. For year 2003, we assume that the shares of each subproduct of Petroleum Products used in different sectors, in real units, were the same as in year 2004. We then use deflators provided for 511 sectors in each year's I-O table to convert them into nominal units. For year 2007 we utilize information from the 2006 detailed table to conduct a similar approximation. On the column side, we apply a procedure analogous to the one explained in the previous section. 
predicted responsiveness of sectoral prices to prices of imported oil and natural gas.

Figure 5.15 presents the results. Panel (A) is for plastic and related products, (B) is for gasoline, (C) is for electricity, and (D) is for the weighted average of manufactured consumer goods. All of these are based on the nominal I-O tables. Lastly, panel (E) is similar to panel (D) except that it is based on the real I-O table.

Note that in all cases, with the exception of gasoline, ${ }^{17}$ the nominal I-O tables predict increases in the responsiveness. This is natural, from what we have seen so far: as oil prices increase, the share of oil and related products in overall production cost returns to be large, and thus their prices are expected to become more sensitive to oil prices. We have seen that our TVPVAR results indicate, in most cases, increases in the estimated pass-through rates of oil during this period: in that sense, they are consistent with the predictions from the I-O tables. However, the magnitudes are very different. Note that the nominal I-O tables predict swift and sharp increases in oil price sensitivities: for the average of manufactured consumer goods prices, predictions on oil price pass-through in figure 5.14, panel (D), increases by 58.1 percent between 2000 and 2007. On the other hand, according to numbers underlying figure 5.5, panel $(\mathrm{C})$, the estimated pass-through rate at the twenty-fourth month horizon increased between 2002 (its bottom) and 2007 by only 15.7 percent, and even for the period between 2002 and 2009, the rate of increase was 32.4 percent.

What accounts for the discrepancies between the TVP-VAR results and the predictions from the nominal I-O tables? We can think of several possible explanations. First, our TVP-VAR estimation uses the fixed weight Laspeyres price indices: ${ }^{18}$ the data for the post-2005 period uses the year 2005 weights. Thus, the rapidly increasing nominal weights of oil-related products after 2005 are not reflected in those indices. Hence, our estimation could have underestimated the true extent of the increase in the pass-through rate, which was caused by the oil price increase in this period. The second hypothesis is that, around 2000 , there was a factor that pushed down the pass-through rate in Japan. One possible cause would be that the Bank of Japan's monetary policy stance suddenly gained enhanced credibility around this period. This is not totally impossible: amendment of the Bank of Japan Law in 1998 gave greater independence to Japan's central bank. ${ }^{19}$ Another possible reason is that, due to deregulation, the labor market became more

17. The predicted responsiveness of gasoline is large in 2000 because our estimated tax revenue from gasoline tax for this year was small. We suspect this is related to changes in tax treatment of diesel, which is a close substitute for gasoline, that happened around this time.

18. Chained price indices were not available for long enough time periods.

19. It should also be remembered, however, that this period was a difficult time for the central bank policy. Due to the zero bound on the nominal interest rate, there was not much room to lower the interest rate. The still sluggish economy implied that rate hikes, even small ones, would have been politically vastly unpopular. 

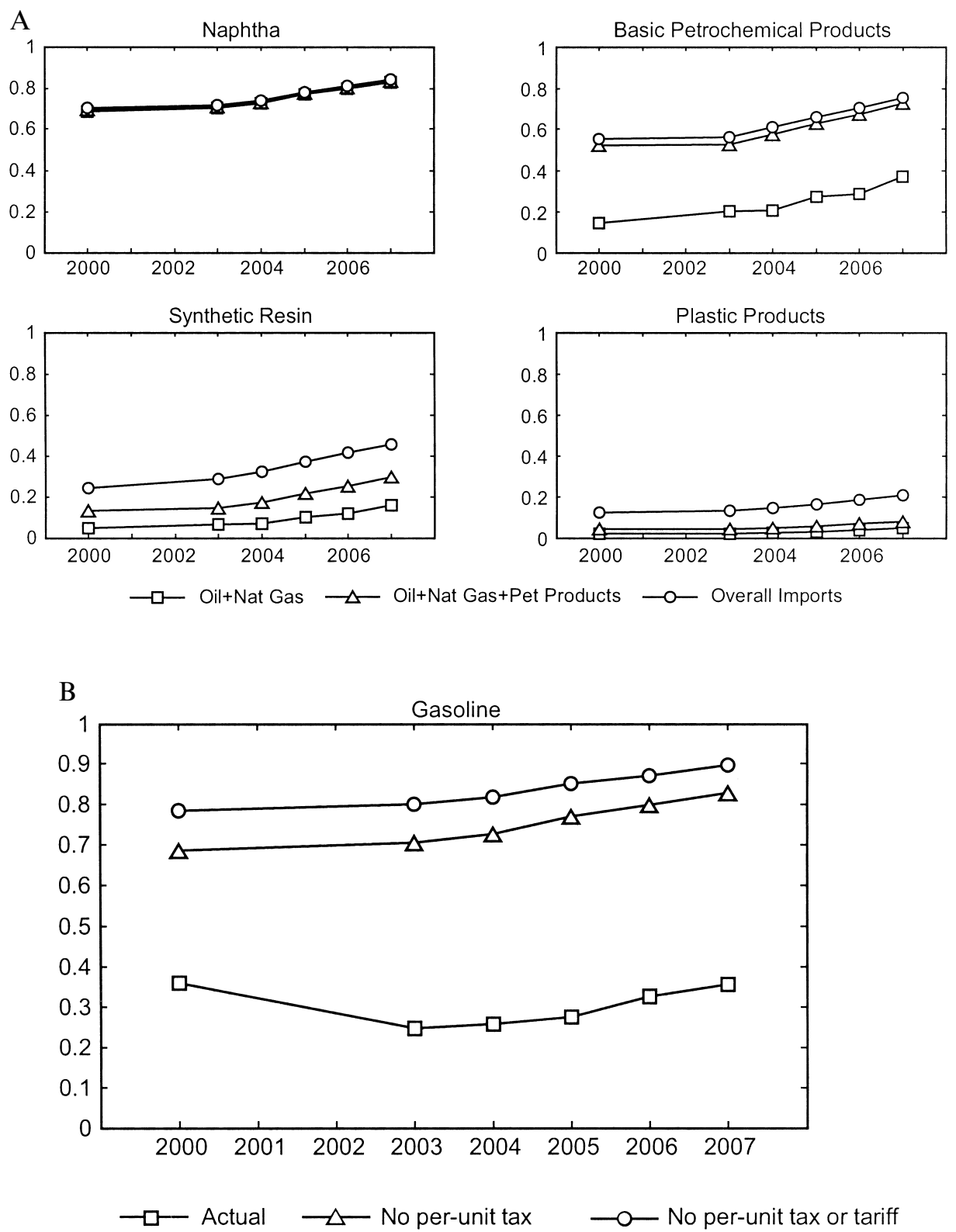

Fig. 5.15 Predicted responses for the 2000s: $A$, Plastic and related products, based on nominal I-O tables; $B$, Gasoline, under actual and hypothetical tex systems, based on nominal I-O tables; $C$, Electricity, based on nominal I-O tables; $D$, Overall manufactured consumer goods prices, based on nominal I-O tables; $E$, Overall manufactured consumer goods prices, based on real I-O tables 
C

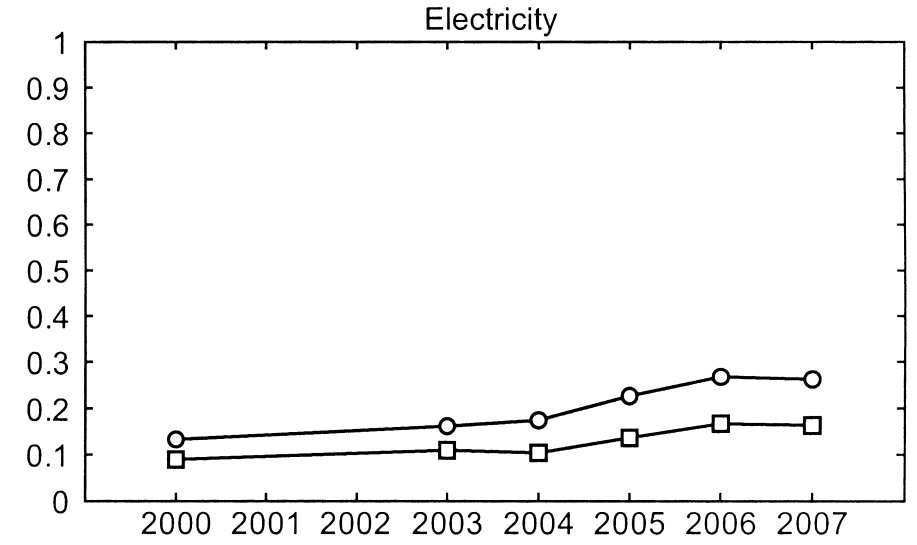

D $0.2 \quad$ Consumer goods, manufacturing only

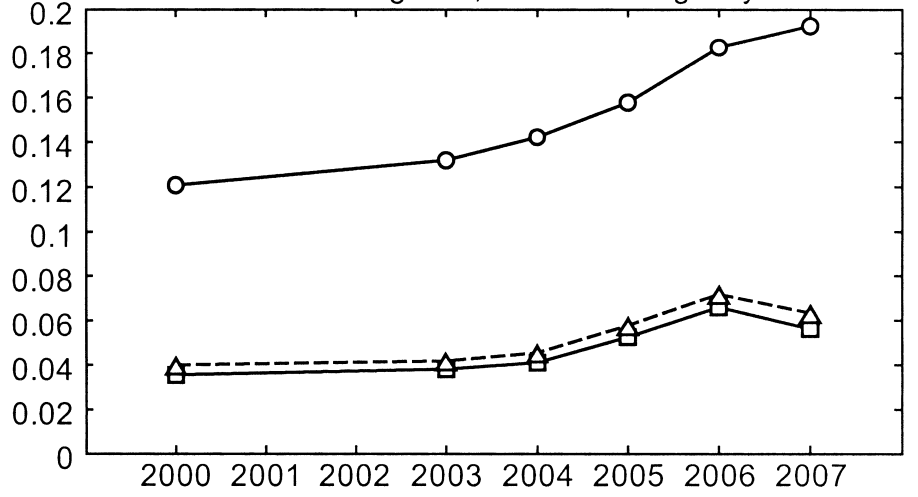

$\mathrm{E}$

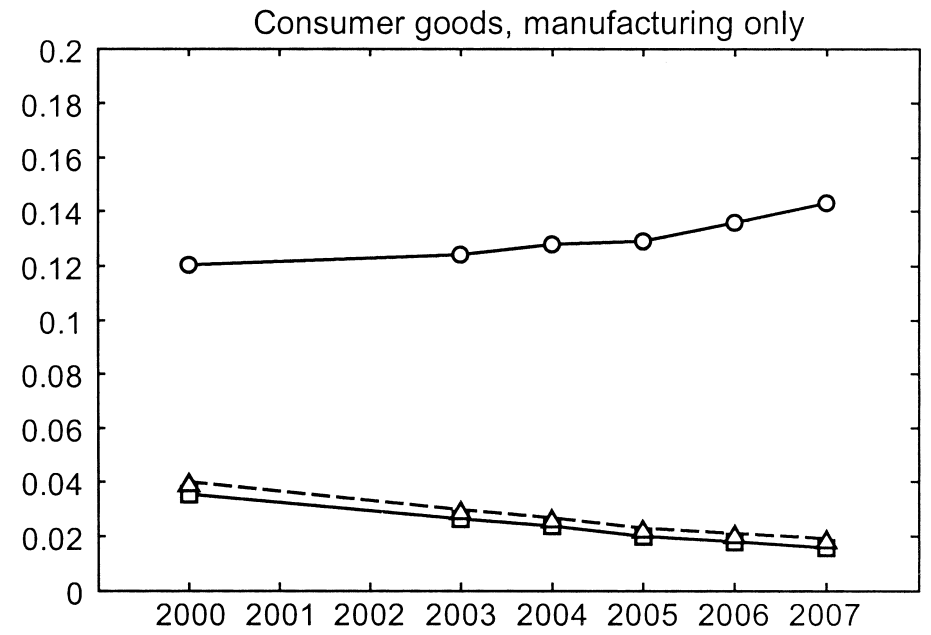

$\rightarrow-$ Oil + Nat Gas $-\Delta-$ Oil+Nat Gas + Pet Products $-0-$ Overall Imports

Fig. 5.15 (Cont.) 
flexible. ${ }^{20}$ The third hypothesis is that firms perceived the oil price increase during this period to be very temporary (which turned out to be the case eventually), thus did not wish to respond to such a shock. Further analyses of this period would be needed to investigate the plausibility of each of the hypotheses.

Finally, panel (E) indicates that the relative quantity factor contributed greatly to reduce predicted pass-through of oil prices. This is consistent with our previous finding that this factor was important for the short period of 1980 to 1985 . In a short period of exceptionally high oil prices, households and firms adjust quite rapidly to reduce dependence on oil-intensive products and inputs. This kind of flexibility has certainly helped alleviate the negative impact of rapidly rising oil prices of this period.

\subsection{Conclusions}

In this chapter, we have investigated factors behind the declining passthrough rate of oil prices to Japanese domestic prices. We have found that, for the period 1980 to 2000, the main driving force behind the decline is the price level of oil itself. As oil became a less important cost item for firms, they naturally decided to respond less to its price changes. Consistently with this view, we find increasing pass-through rates in many of our TVP-VAR results for the 2000s, when oil prices were on the rise. However, at this point, those increases seem a little muted and delayed compared to the sharp increase in oil prices during this period. Investigating this matter further once more data becomes available for this period will be an important topic for future research.

\section{Appendix}

\section{TVP-VAR}

In this appendix, we explain our time varying parameter (TVP-) VAR methodology based on Kim and Nelson (1999). Consider the following VAR model with $K$ variables and $L$ lags, in which the coefficients are varying over time with a specific dynamic structure.

$$
\begin{gathered}
\mathbf{y}_{t}=x_{t} \boldsymbol{\beta}_{t}+\boldsymbol{e}_{t}, \quad t=1,2,3, \ldots, T, \\
\boldsymbol{\beta}_{t}=\boldsymbol{\beta}_{t-1}+v_{t}, \\
e_{t} \sim \text { i.i.d. } N(0, R),
\end{gathered}
$$

20. On the other hand, the rapid aging of the Japanese society increased the share of workers with high seniority at workplaces, which might have reduced flexibility of the labor market. 
and

(A4)

$$
v_{t} \sim \text { i.i.d. } N(0, Q),
$$

where the vector $\mathbf{x}_{\mathbf{t}}$ consists of lagged dependent variables. In this specification, we assume that the coefficient vector follows a random walk, but Kim and Nelson (1999) allow a more general VAR(1) specification. The dimensions of the vectors and matrices are as follows:

$$
\begin{gathered}
\mathbf{x}_{\mathbf{t}}:(K \times(K \times L+1)) ; \boldsymbol{y}_{t}:(K \times 1) ; \boldsymbol{\beta}_{t}:((K \times L+1) \times 1) ; R:(K \times K) ; \\
\text { and } Q:((K \times L+1) \times(K \times L+1)) .
\end{gathered}
$$

We consider estimating this model by the Kalman filter. Note that, in implementing this estimation, we need to specify the matrices $Q$ and $R$, known as "hyper-parameters." We introduce the following notations.

$\boldsymbol{\beta}_{t \mid s}$ : expectation of $\boldsymbol{\beta}_{t}$, conditional on information available in period $s$.

$P_{t \mid s}$ : variance-covariance matrix of $\boldsymbol{\beta}_{t}$, conditional on information available in $s$.

$\mathbf{y}_{t \mid s}=E\left(\mathbf{y}_{\mathbf{t}} \mid \Psi_{s}\right)=\mathbf{x}_{\mathbf{t}} \boldsymbol{\beta}_{t \mid s}$ : forecast of $\mathbf{y}_{\mathbf{t}}$ given information available in period $s$.

$\boldsymbol{\eta}_{t \mid s}=\mathbf{y}_{t}-\mathbf{y}_{t \mid t-1}:$ prediction error.

$f_{t \mid s}=E\left(\boldsymbol{\eta}_{t \mid s}^{2}\right)$ : conditional variance of the prediction error.

Given the information available up to period $t-1$, the prediction rules for period $t$ are written as follows:

$$
\boldsymbol{\beta}_{t \mid t-1}=\boldsymbol{\beta}_{t-1 \mid t-1}, P_{t \mid t-1}=P_{t-1 \mid t-1}+Q \text {, and } f_{t \mid t-1}=\mathbf{x}_{\mathbf{t}} P_{t \mid t-1} \mathbf{x}_{\mathbf{t}}^{\prime}+R .
$$

Define the prediction errors in period $t$ as:

$$
\boldsymbol{\eta}_{t \mid t-1}=\mathbf{y}_{t}-\boldsymbol{y}_{t \mid t-1}=\boldsymbol{y}_{t}-\mathbf{x}_{\mathbf{t}} \boldsymbol{\beta}_{t \mid t-1} .
$$

Then the updating rules are given by

$$
\boldsymbol{\beta}_{t \mid t}=\boldsymbol{\beta}_{t \mid t-1}+K_{t} \boldsymbol{\eta}_{t \mid t-1}
$$

and

$$
P_{t \mid t}=P_{t \mid t-1}-K_{t} x_{t} P_{t \mid t-1}
$$

where

$$
K_{t}=P_{t \mid t-1} \mathbf{x}_{\mathbf{t}}^{\prime} f_{t \mid t-1}^{-1} \text { (Kalman gain). }
$$

In our estimation, the initial values $\boldsymbol{\beta}_{0 \mid 0}$ and $P_{0 \mid 0}$, as well as the hyperparameters $Q$ and $R$, are chosen in the following manner. We first estimate a reduced-form VAR using the entire sample. The initial coefficient vector $\boldsymbol{\beta}_{0 \mid 0}$ is set to be equal to the estimated coefficient vector from this estimation, and $P_{0 \mid 0}$ is set to be equal to $h_{0}$ times the estimated variance covariance matrix of the coefficients. Denote the variance covariance matrix of the estimated 
coefficients as $\hat{Q}$ and the residual variance covariance matrix as $\hat{R}$. Then we impose the following relationships:

$$
Q=h_{Q} \cdot \hat{Q},
$$

and

$$
R=h_{R} \cdot \hat{R},
$$

where both $h_{Q}$ and $h_{R}$ are positive constants. This restriction greatly reduces the number of parameters to be chosen by the researcher.

We set $h_{0}=10$ in all the estimations reported in the text. ${ }^{21}$ For $h_{Q}$ and $h_{R}$, we try several different values and choose a combination that minimized the likelihood:

$$
l(\theta)=-\frac{1}{2} \sum_{t=1}^{T} \ln \left((2 \pi)^{n}\left|f_{t \mid t-1}\right|\right)-\frac{1}{2} \sum_{t=1}^{T} \boldsymbol{\eta}_{t \mid t-1}^{\prime} f_{t \mid t-1}^{-1} \boldsymbol{\eta}_{t \mid t-1} .
$$

In practice, we tried four different values $(0.01,0.025,0.05$, and 0.1$)$ for $h_{O}$, and three different values $(0.9,1$, and 1.1$)$ for $h_{R}$ (for the latter, the value of 1 was usually preferred by the likelihood criterion).

\section{References}

Bernanke, B. S., M. Gertler, and M. Watson. 1997. Systematic monetary policy and the effects of oil price shocks. Brookings Papers on Economic Activity 1:91-142.

Blanchard, O. J., and J. Gali. 2007. The macroeconomic effects of oil shocks: Why are the 2000s so different from the 1970s? NBER Working Paper no. 13368. Cambridge, MA: National Bureau of Economic Research, September.

Blinder, A. S., and J. B. Rudd. 2008. The supply-shock explanation of the Great Stagflation revisited. NBER Working Paper no. 14563. Cambridge, MA: National Bureau of Economic Research, December.

. 2009. Oil shocks redux. VOX website. Available at: http://www.voxeu.org/ index.php?q=node/2786.

De Gregorio, J., O. Landerretche, and C. Neilson. 2007. Another pass-through bites the dust? Oil prices and inflation. Bank of Chile Working Paper no. 417.

Hooker, M. A. 1996. What happened to the oil price-macroeconomy relationship? Journal of Monetary Economics 38 (October): 195-213.

2002. Are oil shocks inflationary? Asymmetric and nonlinear specifications versus changes in regime. Journal of Money, Credit, and Banking 34 (May): 540-61.

International Labor Office. 2004. Consumer price index manual: Theory and practice. United Nations: International Labour Organization.

21. It is customary to choose a relatively large number for this parameter, so that the results are not very sensitive to the initial values. We avoid reporting results for the first five years of the sample, namely 1975 to 1979 , in an effort to further minimize the effects of those initial values. 
Ito, T., and K. Sato. 2008. Exchange rate changes and inflation in post-crisis Asian economies: Vector autoregression analysis of the exchange rate pass-through. Journal of Money, Credit, and Banking 40:1407-38.

Japan Fair Trade Commission. 2004. Research note on the state of gasoline distribution (in Japanese). Tokyo: JFTC.

Jongwanich, J., and D. Park. 2008. Inflation in developing Asia: Pass-through from global food and oil price shocks. Working Paper, Asian Development Bank.

Kilian, L. 2008. The economic effects of energy price shocks. Journal of Economic Literature 46 (4): 871-909.

Kim, C.-J., and C. R. Nelson. 1999. State-space models with regime-switching: Classical and Gibbs-sampling approaches with applications. Cambridge, MA: MIT Press.

Shioji, E., and T. Uchino. 2009. Kawase reto to genyu kakaku hendo no pasu suru ha henka shitaka (Have pass-through of the exchange rate and oil prices changed?). Bank of Japan Working Paper Series no. 09-J-8.

Shiratsuka, S. 2005. Waga kuni no shouhisha bukka shisuu no keisoku gosa (Measurement errors in the Japanese Consumer Price Index). Bank of Japan Review no. 2005-J-14.

\section{Comment Yuko Hashimoto}

This chapter examines the responsiveness of Japanese price indices to fluctuations in crude oil prices using various econometric methodologies. Shioji and Uchino find that the continued decline in the pass-through rate of oil prices to Japanese prices can mainly be explained by changes in cost structures in the Japanese manufacturing industry. That is, a decrease in oil prices has lowered the share of oil prices in the total cost and thus Japanese domestic prices have become seemingly less sensitive to fluctuations in oil prices. The authors conclude that this cheaper oil "price" effect explains more of the declining pass-through rate than the "quantity" effect, which captures a substitution between oil-related goods and nonoil related goods (i.e., consumers switch to nonoil goods when oil prices rise sharply and therefore retail prices are not affected as much from the oil price hike). This finding is consistent with the estimation exercise for the sample period up to May 2009 in that the recent oil price surge has clearly pushed up the pass-through rate to Japanese price indices. The authors also show that the existence of taxes has contributed to lower the gasoline and diesel price responses to oil price fluctuations. In other words, for a high oil import-dependent country like Japan, these taxes, among others, have also helped mitigate oil price shocks on retail prices and further maintain domestic price levels as relatively stable.

This chapter is very well written. The authors derive conclusions and

Yuko Hashimoto is an economist at the International Monetary Fund. 